\title{
AMMONITES, CICLOS TAFONÓMICOS Y CICLOS ESTRATIGRÁFICOS EN PLATAFORMAS EPICONTINENTALES CARBONÁTICAS
}

\author{
Sixto FERNÁNDEZ-LÓPEZ \\ Depto. y UEI de Paleontología, Facultad de Ciencias Geológicas (UCM), e \\ Instituto de Geología Económica (CSIC-UCM). 28040-Madrid.
}

Fernández-López, S. 1997. Ammonites, ciclos tafonómicos y ciclos estratigráficos en plataformas epicontinentales carbonáticas. A Ammonites, taphonomic cycles and stratigraphic cycles in carbonate epicontinental platforms]. Revista Española de Paleontología, 12 (2), 151-174. ISSN 0213-6937.

\begin{abstract}
Some variations of the taphonomic features and the distribution of the recorded associations of ammonites enable to distinguish elemental taphonomic sequences, taphosequences, taphorecords, taphocycles, megataphosequences and supertaphocycles in carbonate epicontinental platforms resulting of relative sea-level changes. The identification of taphonomic cycles is important in interpreting stratigraphic cycles of epicontinental platforms, when no evidence of coastal onlap is preserved and fossiliferous sediments of outer platform are widely developed.

Five environmental cycles of deepening/shallowing were developed in the Castiliane, Aragonese and Tortosa platforms during the Middle Jurassic: four of them of median deepening (early Aalenian, middle Aalenian-early Bajocian, Bathonian and Callovian) and one of them of advanced deepening (late Bajocian). Ammonite taphorecords of the Opalinum Biozone represent the last terms of a shallowing upwards megataphosequence which began in the late Toarcian. The maximum relative sea-level rise and the maximum deepening were reached during the Niortense Biochron (late Bajocian). Episodes of maximum relative sea-level fall during the Middle Jurassic correspond to the stratigraphic discontinuities of middle Aalenian (Murchisonae Biochron) and late Callovian (Lamberti Biochron). The Middle Jurassic sediments between these stratigraphic discontinuities, from middle Aalenian to Upper Callovian, represent a supercycle of second order in the Iberian Basin.
\end{abstract}

Key words: Fossilization, biostratinomy, early fossildiagenese, applied taphonomy, sequence stratigraphy, Middle Jurassic, Iberian Basin.

\section{RESUMEN}

Algunas variaciones de los caracteres tafonómicos y la distribución de las asociaciones registradas de ammonites en las plataformas epicontinentales carbonáticas permiten distinguir secuencias tafonómicas elementales, tafosecuencias, taforregistros, tafociclos, megatafosecuencias y supertafociclos que son el resultado de cambios relativos del nivel del mar. La identificación de los ciclos tafonómicos es de máxima importancia para la interpretación de los ciclos estratigráficos de las plataformas epicontinentales mesozoicas, cuando no hay evidencias de las variaciones de la línea de costa y los sedimentos fosilíferos de plataforma externa están ampliamente desarrollados.

Cinco ciclos ambientales de profundización/somerización se desarrollaron en las plataformas Castellana, Aragonesa y de Tortosa durante el Jurásico Medio: cuatro de profundización media (durante el Aaleniense inferior, el Aaleniense medio-Bajociense inferior, el Bathoniense y el Calloviense) y uno de profundización avanzada (durante el Bajociense superior). Los taforregistros de ammonites de la Biozona Opalinum representan los últimos términos de una megatafosecuencia de somerización iniciada durante el Toarciense superior. La máxima profundización y el máximo transgresivo se alcanzó durante el Biocrón Niortense (Bajociense superior). Los episodios de máxima somerización durante el Jurásico Medio, que representan máximos regresivos, corresponden a las discontinuidades del Aaleniense medio (Biocrón Murchisonae) y del Calloviense superior (Biocrón Lamberti). Los sedimentos del Jurásico Medio comprendidos entre estas dos discontinuidades estratigráficas, desde el Aaleniense medio hasta el Calloviense superior, representan un superciclo de segundo orden en la Cuenca Ibérica.

Palabras clave: Fosilización, bioestratinomía, fosildiagénesis temprana, tafonomía aplicada, estratigrafía secuencial, Jurásico Medio, Cuenca Ibérica. 


\section{INTRODUCCIÓN}

Algunas variaciones en el estado de conservación de los ammonites y la distribución de las asociaciones registradas son el resultado de, y permiten reconstruir, las diferencias entre distintos ambientes sedimentarios de las plataformas epicontinentales mesozoicas (FernándezLópez, 1997). Las asociaciones registradas de ammonites que se encuentran en rocas sedimentarias formadas en ambientes distales y profundos de plataforma muestran caracteres distintivos respecto a las de ambientes proximales y someros. Teniendo en cuenta las variaciones en el estado de conservación de los restos de ammonites, también se pueden estimar las variaciones en el grado de confinamiento o de comunicación de los paleoambientes sedimentarios de plataforma, así como las diferencias en el grado de turbulencia, en la tasa de sedimentación y en la tasa de acumulación de sedimentos o velocidad de sedimentación.

El objetivo principal del presente trabajo es mostrar que algunas variaciones en el estado de conservación de las asociaciones registradas de ammonites también

$$
\log _{10} \text { años }
$$

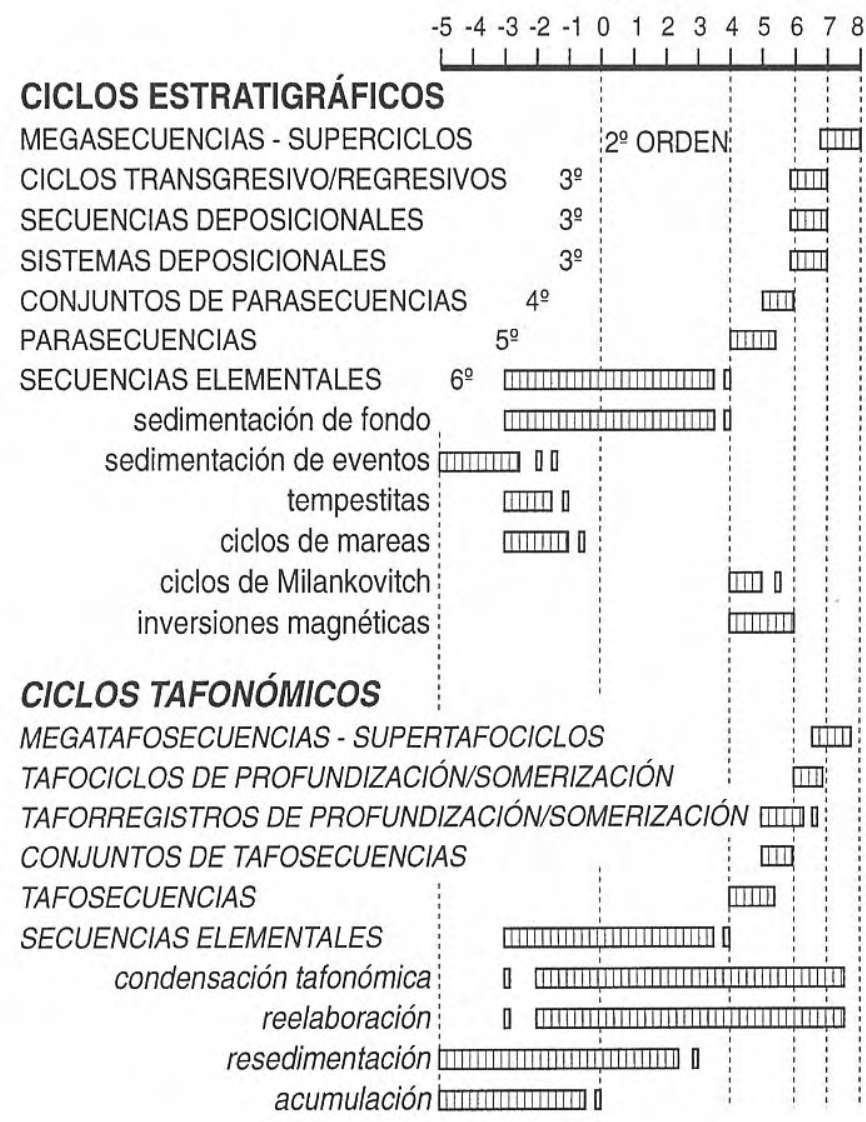

Figura 1. Resolución temporal de los ciclos estratigráficos y de los ciclos tafonómicos de distinto orden, desarrollados en las plataformas epicontinentales carbonáticas, así como de algunos procesos mencionados en el texto. permiten identificar e interpretar cambios relativos del nivel del mar, cíclicos y de diferente orden de magnitud, ocurridos en las plataformas epicontinentales mesozoicas. Además del interés paleobiológico que pueden tener, estos datos tafonómicos son de interés estratigráfico y sedimentológico porque posibilitan una contrastación independiente de los ciclos distinguidos en estratigrafía secuencial.

\section{CICLOS ESTRATIGRÁFICOS Y CICLOS TAFONÓMICOS}

Los ciclos estratigráficos son el resultado de modificaciones ambientales de carácter cíclico (por ejemplo, modificaciones eustáticas, climáticas y/o tectónicas). En el registro estratigráfico es posible distinguir secuencias y ciclos estratigráficos de distinto orden que son el resultado de cambios relativos del nivel del mar (Fig. 1). Debido a modificaciones ambientales de carácter cíclico (cambios eustáticos, climáticos, tectónicos...), las sucesivas asociaciones registradas de una región o de una cuenca sedimentaria también pueden presentar variaciones cíclicas en sus caracteres secundarios resultantes de la alteración tafonómica. Un ciclo tafonómico está constituido por dos o más asociaciones-registradas, topológicamente sucesivas y consecutivas, que muestran variaciones cíclicas en sus caracteres secundarios, como resultado de un ciclo de cambio ambiental.

Las secuencias estratigráficas elementales, las parasecuencias, los conjuntos de parasecuencias, las tafofacies, los sistemas deposicionales, los cortejos sedimentarios, las secuencias deposicionales de tercer orden, los ciclos transgresivo/regresivos de tercer orden y las megasecuencias o los superciclos son términos genéticos de estratigrafía secuencial que permiten agrupar y distinguir los cuerpos rocosos del registro estratigráfico. Las secuencias tafonómicas elementales, las tafosecuencias, los conjuntos de tafosecuencias, los taforregistros, los tafociclos de profundización/somerización, las megatafosecuencias y los supertafociclos, que serán tratados en los siguientes apartados, son términos genéticos de tafonomía que permiten agrupar y distinguir los elementos conservados, las poblaciones tafónicas o las asociaciones conservadas del registro fósil.

La identificación de secuencias y ciclos tafonómicos, en vez de secuencias y ciclos estratigráficos, es necesaria para averiguar las diferencias genéticas entre el registro fósil y el registro estratigráfico. Téngase en cuenta, por ejemplo, que las sucesivas asociaciones registradas que constituyen varios taforregistros sucesivos generados en distintas condiciones ambientales pueden formar una asociación condensada que se encuentra en un sólo nivel estratigráfico o pueden corresponder a un intervalo sin registro estratigráfico (Fernández-López, 1985b, 1986, 1987b, 1991, 1995).

Las posibles relaciones entre los procesos cíclicos que han condicionado la continuidad/discontinuidad del registro estratigráfico y la del registro fósil en las 
plataformas epicontinentales carbonáticas pueden ser contrastadas teniendo en cuenta las duraciones relativas de los distintos procesos (Fig. 1). Para realizar estas calibraciones entre ciclos estratigráficos y ciclos tafonómicos han sido tenidos en cuenta los datos geocronométricos y geocronológicos publicados por Gradstein et al. (1994), Callomon (1995), Odin et al. (1995) y Gradstein y Ogg (1996).

\section{SECUENCIAS ELEMENTALES}

Las secuencias estratigráficas elementales, de espesor centimétrico o decimétrico, son ciclos estratigráficos de sexto orden y ritmos cuya ciclicidad es inferior a los 20.000 años. Las secuencias elementales que se suelen formar en las plataformas epicontinentales carbonáticas son el resultado de variaciones graduales en la turbulencia y en la tasa de sedimentación (Fig. 2).

En los ambientes abiertos de plataforma externa, cuando la disminución en la tasa de sedimentación está asociada a incremento en el grado de turbulencia de las aguas, puede haber aumento gradual en la concentración de conchas de ammonites y en el grado de herencia tafonómica de las asociaciones, al mismo tiempo que se intensifican los procesos tafonómicos de biodegradacióndescomposición, encostramiento, relleno sedimentario, concreción, abrasión, bioerosión, fragmentación, reorientación, desarticulación, reagrupamiento y removilización de los restos de ammonites. Así se han formado también las winnowed beds descritas por Monaco (1995). En cambio, en los ambientes confinados de plataforma externa, cuando el aumento en la tasa de

Figura 2. Secuencias elementales frecuentes en las parasecuencias del Jurásico Medio de la Cordillera Ibérica, con indicación de las variaciones en el grado de turbulencia y en la tasa de sedimentación. El grado de turbulencia aumenta y la tasa de sedimentación disminuye durante el desarrollo de las parasecuencias en los ambientes de plataforma externa carbonática. La sedimentación de fondo que da lugar a estas secuencias elementales también experimenta variaciones en el grado de turbulencia, inversamente proporcionales a la tasa de sedimentación. No obstante, el grado de turbulencia es creciente en los ambientes abiertos y decreciente en los ambientes confinados durante el desarrollo de las secuencias elementales. Debido a estas variaciones ambientales, durante el desarrollo de estas secuencias elementales, el grado de herencia tafonómica (estimado por la proporción de elementos reelaborados) y la concentración de los restos de ammonites aumentan en los ambientes abiertos, pero los valores de estos dos parámetros disminuyen en los ambientes confinados.

\section{SECUENCIAS ELEMENTALES}

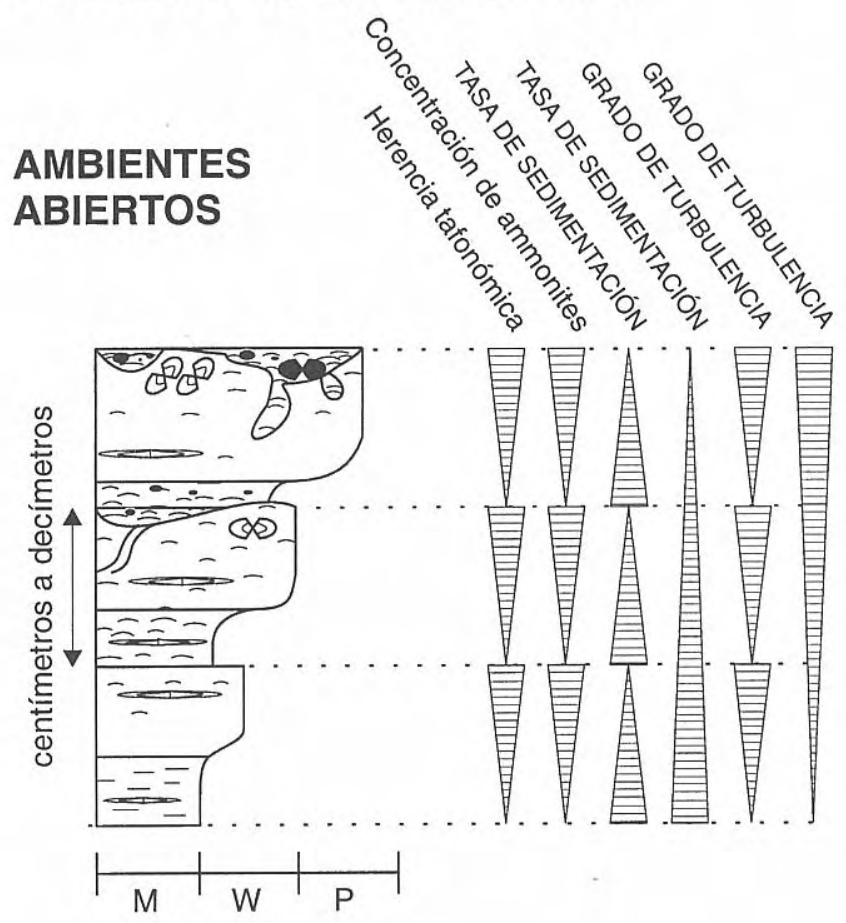

\section{AMBIENTES CONFINADOS}
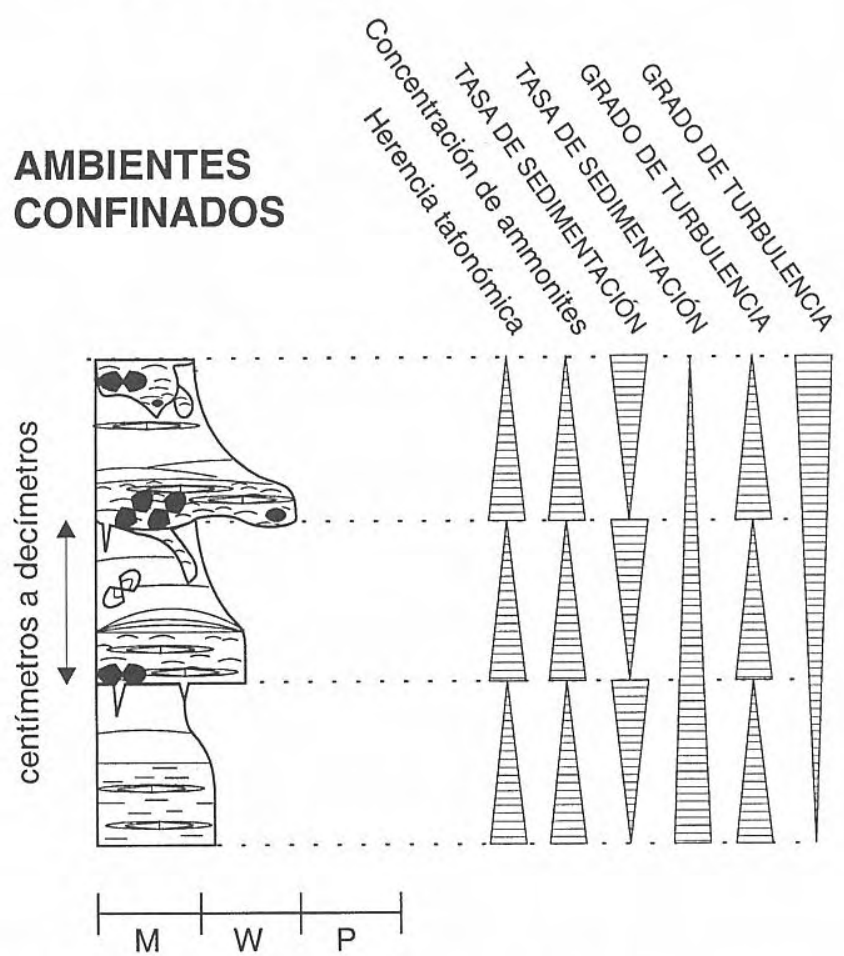

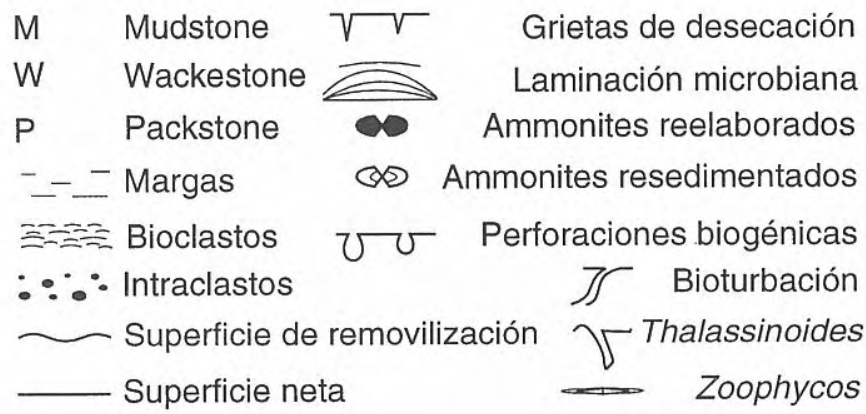




\section{SECUENCIAS ELEMENTALES EN AMBIENTES CONFINADOS DE PLATAFORMA EXTERNA}

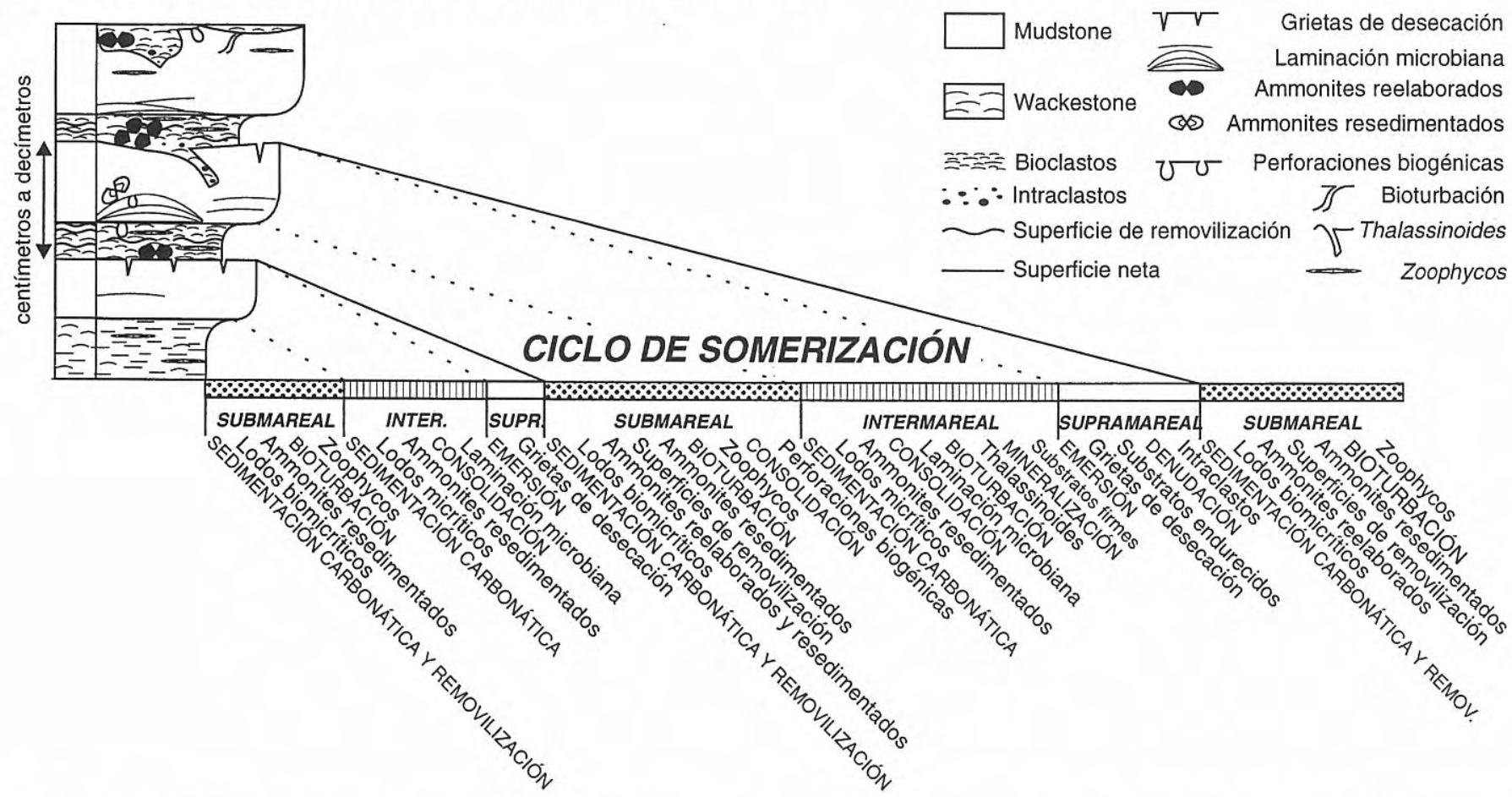

Figura 3. Ejemplo de ciclo de somerización y secuencias elementales de ambientes confinados de plataforma externa afectados por las mareas, en materiales del Bajociense inferior de la Plataforma Castellana (Columna El Pedregal, Guadalajara, en Fernández-López, 1985c).

sedimentación está asociado a disminución del grado de turbulencia de las aguas, por los mismos procesos tafonómicos se generan asociaciones de ammonites con valores decrecientes de concentración y herencia tafonómica, entre otros caracteres secundarios (Figs. 3 y 4). Las causas de estas secuencias elementales pueden ser muy variadas. Algunos autores consideran que los ciclos de mareas vivas-muertas, mensuales o semestrales (equinocciales) pueden ser una causa de esta periodicidad (Ferry y Mangold, 1995) en tanto que otros autores las relacionan con ciclicidad climática (Ferry, 1991; Vera Torres, 1994; Reboulet, 1995; Miall, 1995, 1997).

Como se indica en la Fig. 3, cada secuencia elemental es de espesor centimétrico y su continuidad lateral no suele sobrepasar unos pocos metros. Cada una de estas secuencias elementales representa un episodio de sedimentación de fondo, en condiciones de turbulencia decreciente y tasa de sedimentación creciente. Cada secuencia elemental de este tipo está constituida, en su parte inferior, por margas biodetríticas y calizas wackestone formadas en ambientes submareales, después de una fase de emersión y no-depósito o erosión local. Durante los episodios submareales se formaron superficies de removilización, bioclastos, intraclastos y estructuras de bioturbación de tipo Zoophycos; estos niveles basales contienen localmente altas concentraciones de moldes internos concrecionales de ammonites reelaborados, con frecuentes encostramientos y perforaciones biogénicas, que pueden presentar patrones de agrupamiento imbricados. Al aumentar el grado de confinamiento en el ambiente de sedimentación, disminuyó el grado de turbulencia y se desarrollaron velos o tapices microbianos sobre el fondo marino; también se produjeron estructuras de bioturbación de tipo Thalassinoides; el potencial de fosilización de las conchas de ammonites disminuyó, y sólo excepcionalmente llegaron algunas conchas derivadas de ammonites, que suelen estar conservadas como ammonites huecos, resedimentados, en posiciones más o menos verticales, con escasas o nulas señales de compactación diagenética gravitacional por cementación temprana de la matriz sedimentaria. Grietas de desecación, substratos endurecidos e intraclastos se formaron durante los episodios supramareales. Las parasecuencias del Bajociense inferior de la Plataforma Castellana pueden llegar a tener varias decenas, algunas incluso más de un centenar, de estas secuencias elementales formadas por la acción de las mareas.

Para interpretar las ritmitas margo-calcáreas formadas en las plataformas carbonáticas someras también es importante distinguir entre sedimentación de fondo y sedimentación de eventos (cf. Aigner, 1985; Brett y Baird, 1986; Fernández-López y Gómez, 1990c; García Ramos et al., 1992; Fürsich y Oschmaann, 1993; López Martínez y Fernández-López, 1993; Brett, 1995). La sedimentación carbonática de fondo en la plataforma externa se caracteriza por presentar variaciones graduales en la tasa de sedimentación inversamente proporcionales a la turbulencia, sean ambientes abiertos o confinados (Fig. 2). En cambio, en las mismas plataformas 


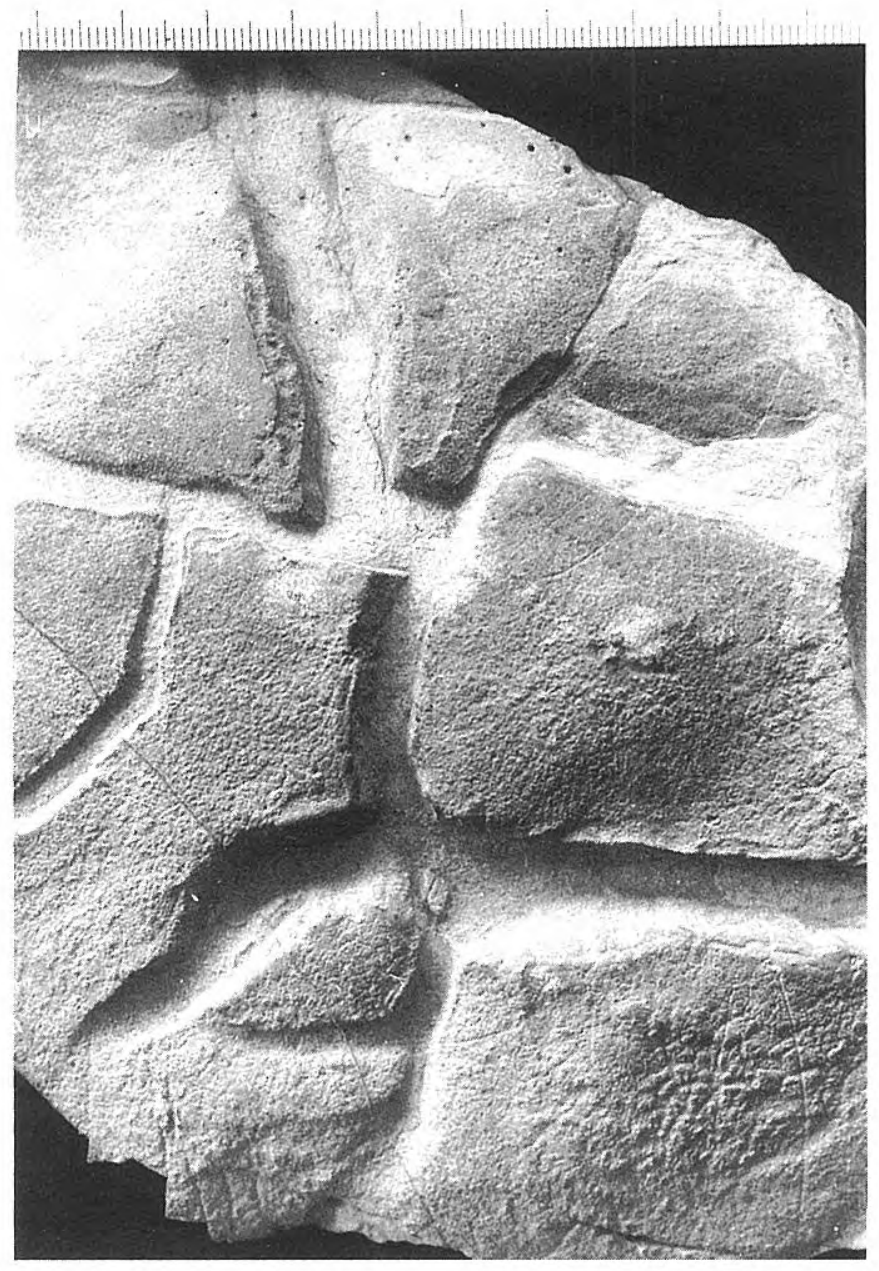

Figura 4. Grietas de desecación en calizas de tipo mudstone del Bajociense inferior de la Plataforma Castellana (Biozona Propinquans, ex Biozona Sauzei; Columna Rambla Monterde, Teruel, nivel 4BH39U160 en Fernández-López, 1985c).

epicontinentales carbonáticas, los eventos de turbulencia dan lugar a depósitos que se caracterizan por haberse formado en condiciones de tasa de sedimentación y grado de turbulencia decrecientes (Fig. 5). El estado de conservación y la distribución de los ammonites permiten identificar y contrastar estos eventos de turbulencia. Por ejemplo, los ammonites incluidos en las tempestitas presentan, junto a la granoclasificación normal o positiva, valores decrecientes de concentración, inclinación, remoción (proporción de elementos resedimentados o reelaborados) y herencia tafonómica (proporción de elementos reelaborados). A diferencia de lo que ocurre en la sedimentación de fondo, las tempestitas, granodecrecientes y de base erosiva o neta, no pueden contener ammonites con patrones de agrupamiento imbricados o con orientación azimutal preferente (Fernández-López, 1997).

Las secuencias tafonómicas elementales están constituidas por dos o más asociaciones-registradas, temporalmente sucesivas, que presentan variaciones graduales en sus caracteres secundarios resultantes de la

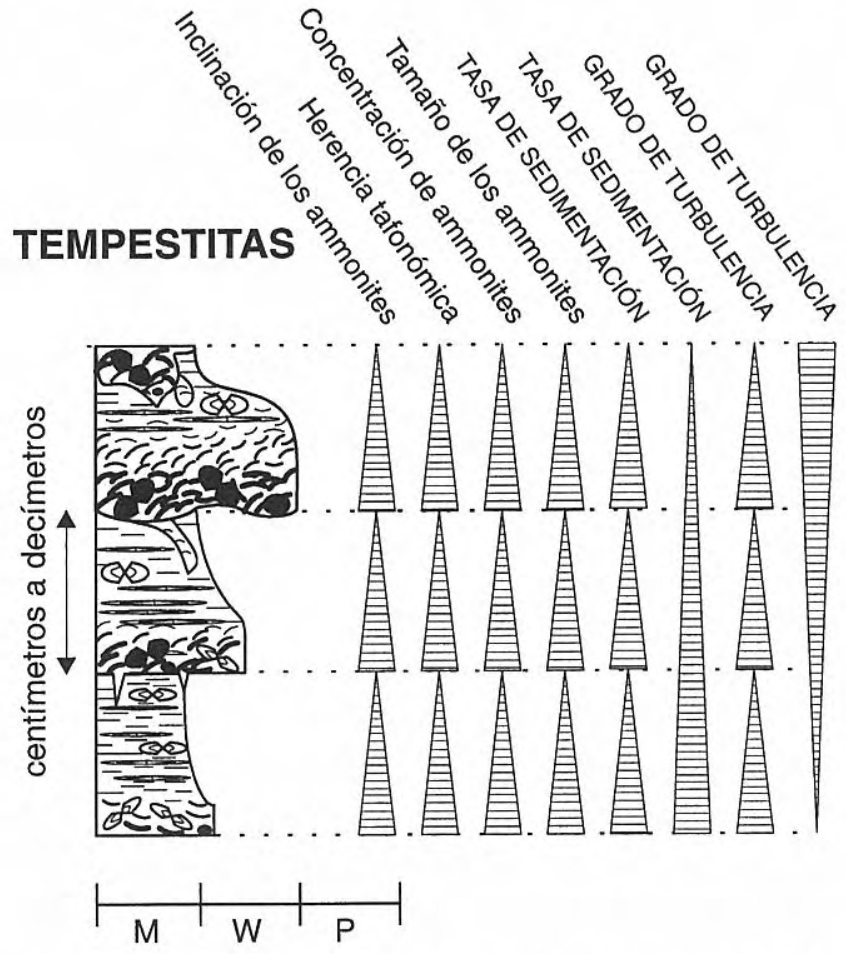

\begin{tabular}{|c|c|c|c|}
\hline M & Mudstone & $\sim$ & Superficie de removilización \\
\hline W & Wackestone & & Superficie neta \\
\hline & Packstone & $\infty$ & Ammonites \\
\hline & $\mathrm{Ma}$ & $\infty$ & Ammonites res \\
\hline & clastos & च & Perforaciones biogén \\
\hline
\end{tabular}

Figura 5. Frecuencias de los diferentes caracteres tafonómicos de los ammonites que se encuentran incluidos en tempestitas del Jurásico Medio de la Cordillera Ibérica. Las sucesivas variaciones en el grado de turbulencia y en la tasa de sedimentación son directamente proporcionales entre sí durante la sedimentación de eventos. Las tempestitas se han formado en condiciones de grado de turbulencia y tasa de sedimentación decrecientes. Los ammonites incluidos en estos depósitos se caracterizan por tener granoclasificación normal o positiva, así como valores decrecientes de base a techo en la concentración, el grado de herencia tafonómica y la inclinación.

alteración tafonómica. Las diferentes asociaciones registradas que constituyen una secuencia tafonómica elemental pueden estar en un mismo nivel estratigráfico, porque la continuidad/discontinuidad del registro fósil no está determinada por la continuidad/discontinuidad del registro estratigráfico (Fernández-López, 1986, 1987b, 1995, fig. 13). 

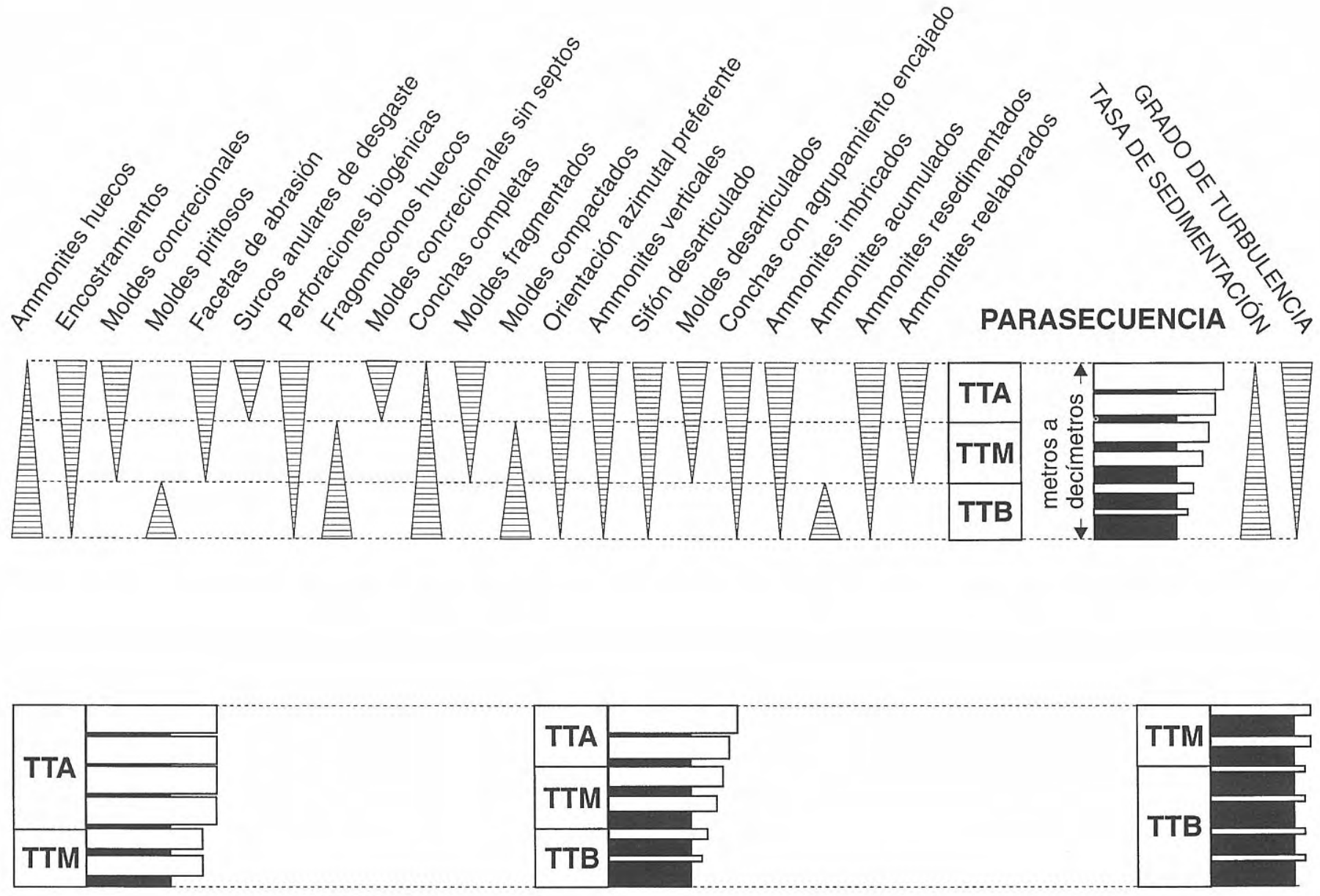

\section{AMBIENTES SOMEROS DE PLATAFORMA PROXIMAL}

Figura 6. Frecuencias de algunos caracteres tafonómicos de los ammonites que se encuentran en secuencias de somerización o parasecuencias de plataforma externa carbonática, y constituyen tafosecuencias positivas o de turbulencia creciente.

\section{PARASECUENCIAS Y TAFOSECUENCIAS}

Los sedimentos carbonáticos de las plataformas epicontinentales someras suelen estar organizados en secuencias de somerización o parasecuencias, de espesor métrico o decimétrico, estrato- y granocrecientes, que representan variaciones en la profundidad relativa, desde ambientes submareales poco profundos hasta ambientes inter- o supramareales. Estas secuencias de somerización o parasecuencias representan variaciones cíclicas de quinto orden (entre 20.000 y 100.000 años, según Einsele, 1992 y Vera Torres, 1994; de unos 100.000 años, en Reboulet, 1995; entre 10.000 y 200.000 años, según Miall, 1995).

Durante el desarrollo de las parasecuencias, las variaciones en el grado de remoción (proporción de elementos resedimentados o reelaborados) y en el grado de herencia tafonómica (proporción de elementos reelaborados) que presentan las asociaciones de ammonites dependen de las variaciones en las tasas de sedimentación y en las tasas de acumulación de sedimentos, más que de las variaciones en el grado de turbulencia de las aguas o en la profundidad (FernándezLópez, 1997). El grado de remoción y el grado de herencia tafonómica de las asociaciones de ammonites suelen ser inversamente proporcionales a la tasa de sedimentación y a la tasa de acumulación de sedimentos o velocidad de sedimentación. Cuando disminuye la tasa de sedimentación y/o la tasa de acumulación de sedimentos, aumenta el grado de remoción y el grado de herencia tafonómica de las asociaciones conservadas y se forman tafosecuencias positivas (Fig. 6). Por el contrario, cuando aumenta la tasa de sedimentación y/o la tasa de acumulación de sedimentos, tienden a disminuir el grado de remoción y el grado de herencia tafonómica de las asociaciones conservadas y se forman tafosecuencias negativas (cf. Fernández-López y Suárez-Vega, 1980; Fernández-López 1985b, 1997; Fernández-López et al., 1985; Fernández-López y Aurell, 1988; Fernández-López et al., 1988; Fernández-López y Gómez, 1990b; Fernández-López y Mouterde, 1994). Estas secuencias 


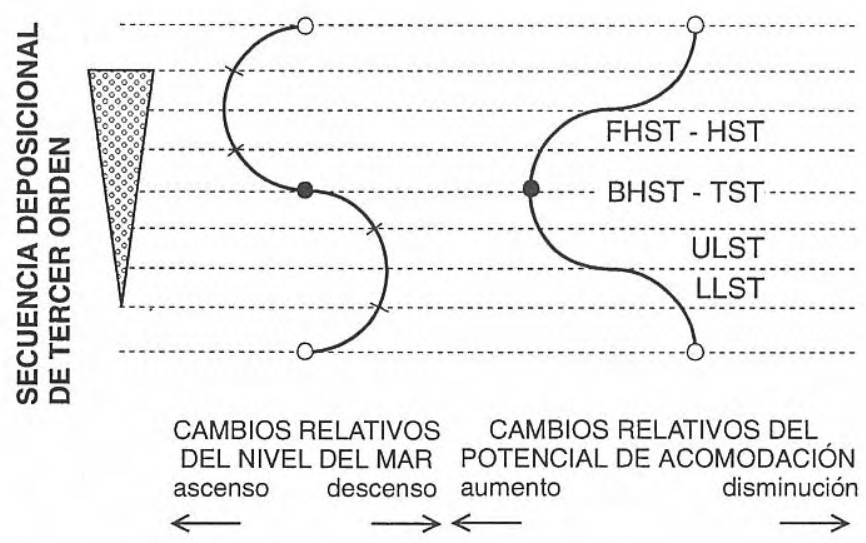

Figura 7. Sistemas deposicionales y fases sucesivas durante el desarrollo de las secuencias deposicionales de tercer orden. LLST $=$ sistema deposicional inferior de bajo nivel (lower lowstand systems tract). ULST = sistema deposicional superior de bajo nivel (upper lowstand systems tract). BHST o TST $=$ sistema deposicional retrogradacional de alto nivel (backstepping highstand systems tract o transgressive systems tract). FHST o HST = sistema deposicional progradacional de alto nivel (forestepping highstand systems tract o highstand systems tract).

tafonómicas positivas y negativas, o tafosecuencias de turbulencia creciente y decreciente, permiten identificar, respectivamente, parasecuencias o secuencias de somerización y secuencias de relleno de quinto orden (Fernández-López 1985b, c, 1997; Fernández-López y Gómez, 1990c, 1991; Fernández-López y Meléndez, 1994; Gómez y Fernández-López, 1994).

Como se indica en la Fig. 6, estas parasecuencias se formaron durante episodios de turbulencia creciente y tasa de sedimentación decreciente, y pueden estar delimitadas por dos superficies consecutivas de máxima inundación. Las sucesivas asociaciones registradas de ammonites, formadas en distintas fases de estas tafosecuencias, presentan diferentes caracteres secundarios y constituyen distintos taforregistros. Las asociaciones registradas que se encuentran en las paracuencias y en las tafosecuencias positivas más completas pueden ser agrupadas en tres taforregistros sucesivos: un taforregistro de turbulencia baja (TTB), un taforregistro de turbulencia moderada (TTM) y un taforregistro de turbulencia alta (TTA). En las primeras asociaciones registradas de las tafosecuencias de este tipo y en los niveles inferiores de estas parasecuencias más completas, donde puede haber elementos acumulados y ammonites piritosos, son más frecuentes las conchas completas, predominan los ammonites huecos (i.e., sin relleno sedimentario en el fragmocono) y los fragmoconos huecos (i.e., sin tabiques), aunque es en estos niveles basales donde los ammonites presentan mayores grados de compactación diagenética gravitacional. Hacia la parte superior de estas parasecuencias carbonáticas son más frecuentes los elementos resedimentados y los elementos reelaborados, aumenta el grado de relleno sedimentario de las conchas y son más frecuentes las conchas con agrupamiento encajado. Los procesos de mineralización temprana también son cada vez más frecuentes, y se forman moldes concrecionales que presentan grados crecientes de abrasión, fragmentación, desarticulación, reorientación y reagrupamiento. Los moldes internos concrecionales, sin deformaciones por compactación diagenética gravitacional, pero con facetas de abrasión formadas antes del enterramiento final, pasan a ser más frecuentes. Los encostramientos y las perforaciones biogénicas, así como los patrones de agrupamiento imbricados, son cada vez más frecuentes, tanto en las conchas como en los moldes internos, y los restos de ammonites pueden llegar a presentar orientación azimutal preferente. Al ser más intensos y duraderos los procesos bioestratinómicos de biodegradación-descomposición aerobia y los de disolución, también aumenta, respectivamente, el grado de desarticulación de los tubos sifonales y la proporción de moldes internos desarticulados. En los estadios finales, cuando hay incluso etapas de emersión, se forman moldes internos concrecionales sin septos (por disolución de los tabiques de las conchas y relleno ulterior de las cavidades con sedimentos) y moldes internos concrecionales con surcos anulares de desgaste. En las secuencias de somerización o parasecuencias formadas en ambientes someros de plataforma externa, predominan los taforregistros de turbulencia alta (TTA); en cambio, en las secuencias de somerización o en las parasecuencias formadas en los ambientes profundos de plataforma distal, predominan los taforregistros de turbulencia baja (TTB).

Las sucesivas tafosecuencias y parasecuencias pueden ser agrupadas en conjuntos o lotes de orden superior, que reflejan variaciones a largo plazo de la profundidad relativa, y suelen estar condicionados por la subsidencia (ciclos estratigráficos de cuarto orden, entre 0,08 y 0,5 Ma, según Vail et al., 1991; entre 0,1 y 0,5 Ma, según Einsele, 1992 y Vera Torres, 1994; de unos 0,4 Ma, según Reboulet, 1995). Estas variaciones a largo plazo pueden ser progradacionales, agradacionales o retrogradacionales (cf. Wilgus et al., 1988; López Martínez and Fernández-López, 1993; Homewood, 1996).

\section{SECUENCIAS Y SISTEMAS DEPOSICIONALES}

Las secuencias deposicionales de tercer orden representan variaciones relativas del nivel del mar con una ciclicidad del orden de un millón de años (entre 0,5 y 5 Ma, según Vail et al., 1991, Gonnin et. al., 1992, 1993 y Jacquin et al., 1992; entre 0,5 y 3 Ma, con una duración media de 0,8 Ma, según Einsele, 1992, Graciansky et al., 1993, Vera Torres, 1994 y Jacquin y Vail, 1995; de 1 Ma, según Fels, 1995; entre 1,5 y 2,5 Ma, en Reboulet, 1995; entre 1 y 10 Ma, según Miall, 1995). Las secuencias deposicionales son de mayor magnitud que las parasecuencias, de quinto orden, o los conjuntos de parasecuencias, de cuarto orden. 
Un ciclo de cambio relativo del nivel del mar, como se suele utilizar en estratigrafía secuencial, comprende desde un descenso relativo del nivel del mar hasta el siguiente descenso relativo (Vail et al., 1987; Wilgus et al., 1988; Ferry, 1991; Rioult et al., 1991; Homewood et al., 1992; Burchette y Wright, 1992; Graciansky et al., 1993; Brett, 1995; Jacquin y Vail, 1995). Las variaciones relativas del nivel del mar determinan cambios relativos del potencial de acomodación de sedimentos y, en las plataformas carbonáticas, cambios relativos en la tasa de producción de sedimentos. La máxima producción de partículas sedimentarias en las plataformas epicontinentales carbonáticas tiene lugar a profundidades del orden de una decena de metros y disminuye rápidamente con la profundidad (Wilson, 1975; James, 1983; Wilgus et al., 1988; Einsele, 1992; Handford y Loucks, 1993; Wright y Burchette, 1996). Los cambios relativos del potencial de acomodación de sedimentos y las variaciones en las tasas de cambio relativo del nivel del mar son dos conceptos fundamentales, no sólo para interpretar las secuencias y los ciclos sedimentarios del registro estratigráfico, sino también para interpretar el carácter secuencial y cíclico del registro fósil en las plataformas epicontinentales carbonáticas.

La curva que representa los cambios relativos del potencial de acomodación de sedimentos puede ser subdividida en cuatro partes para diferenciar cuatro fases sucesivas durante el desarrollo de las secuencias deposicionales de tercer orden (Fig. 7). Diferentes sistemas deposicionales o cortejos sedimentarios se forman en estas cuatro fases de cambio relativo del nivel del mar: 1) sistema deposicional inferior de bajo nivel (LLST); 2) sistema deposicional superior de bajo nivel (ULST); 3) sistema deposicional retrogradacional de alto nivel o transgresivo (BHST o TST); 4) sistema deposicional progradacional de alto nivel (FHST o HST). El conjunto de estos sistemas deposicionales corresponde a una secuencia deposicional de tercer orden. Cada secuencia deposicional representa un ciclo de cambio relativo del nivel del mar, y está limitada por discontinuidades producidas por descensos relativos del nivel del mar.
Los sistemas deposicionales o los cortejos sedimentarios de bajo nivel del mar no suelen estar representados en las plataformas epicontinentales carbonáticas. Cada secuencia deposicional de tercer orden está constituida por depósitos transgresivos, de espesor más o menos limitado, y, fundamentalmente, por depósitos de alto nivel en dichas plataformas (Baum y Vail, 1988; Brett, 1995; Miall, 1995). La máxima producción de carbonatos en las plataformas epicontinentales carbonáticas tiene lugar durante el desarrollo de los sistemas deposicionales progradacionales de alto nivel. Los sistemas deposicionales transgresivos o retrogradacionales de alto nivel sólo rellenan las áreas más profundas o protegidas. Cada sistema deposicional transgresivo o retrogradacional de alto nivel está limitado, en su parte inferior, por una discontinuidad que representa la superficie de transgresión, y, en su parte superior, por una discontinuidad que representa la superficie de máxima inundación. Los sucesivos niveles estratigráficos de estos sistemas deposicionales muestran evidencias del progresivo hundimiento y el consiguiente aumento relativo del nivel del mar (Fig. 8).

Aunque se caracterizan por ser estrato- y granodecrecientes, y suelen contener asociaciones condensadas, los sedimentos de los sistemas deposicionales transgresivos o retrogradacionales presentan distinto grado de condensación sedimentaria según la profundidad relativa de la plataforma. Las secciones condensadas constituidas por sedimentos condensados se forman en las áreas distales y profundas, mientras que las secciones condensadas constituidas por sedimentos expandidos se forman en las áreas proximales y someras (Fernández-López y Gómez, 1991; Gómez y FernándezLópez, 1992, 1994). En cualquiera de estas dos situaciones extremas, la discontinuidad situada por debajo de estos materiales que contienen asociaciones condensadas corresponde al techo de la secuencia deposicional anterior y representa el límite entre las dos secuencias deposicionales consecutivas, aunque pueda resultar paradójico desde el punto de vista granulométrico el incluir los depósitos de mayor tamaño

Figura 8. Sucesivas secuencias elementales identificadas en los materiales de la Biozona Concavum, en el Barranco de la Hontanilla (Plataforma Castellana, Teruel, intervalo estratigráfico entre las superficies de estratificación 1BH21 a 1BH29, facies F4 de acuerdo con la interpretación de Fernández-López y Gómez, 1990c). Después de la formación local de brechas intraformacionales, hubo una fase de sedimentación de lodos biodetríticos (H) que, por bioturbación y cementación local, dieron lugar a un substrato parcialmente consolidado (estadio J), en el que se desarrollaron grietas de desecación, y que llegó a estar litificado debido a fenómenos de emersión y meteorización local (estadio K). En los sucesivos episodios posteriores de sedimentación (L, O, R y T) también se desarrollaron secuencias elementales análogas, que representan de nuevo el paso desde un substrato blando hasta un substrato endurecido (estadios J, N y Q) o firme (estadios I, M, P, S). Los efectos de los procesos de meteorización, emersión, denudación, mineralización, colonización o consolidación temprana fueron cada vez menores en estos sucesivos episodios de sedimentación (H, L, O, R y S), como consecuencia del progresivo hundimiento y del aumento relativo del nivel del mar. Este intervalo estratigráfico, desde el nivel 21 hasta el nivel 29 , tiene $80 \mathrm{~cm}$ de potencia, es estratodecreciente y contiene asociaciones condensadas, pero está constituido por sedimentos expandidos. El intervalo estratigráfico 1BH21-1BH29 es una sección condensada de un sistema deposicional transgresivo o retrogradacional de alto nivel. La superficie de estratificación $1 \mathrm{BH} 21$ es la superficie transgresiva de dicho sistema deposicional. 


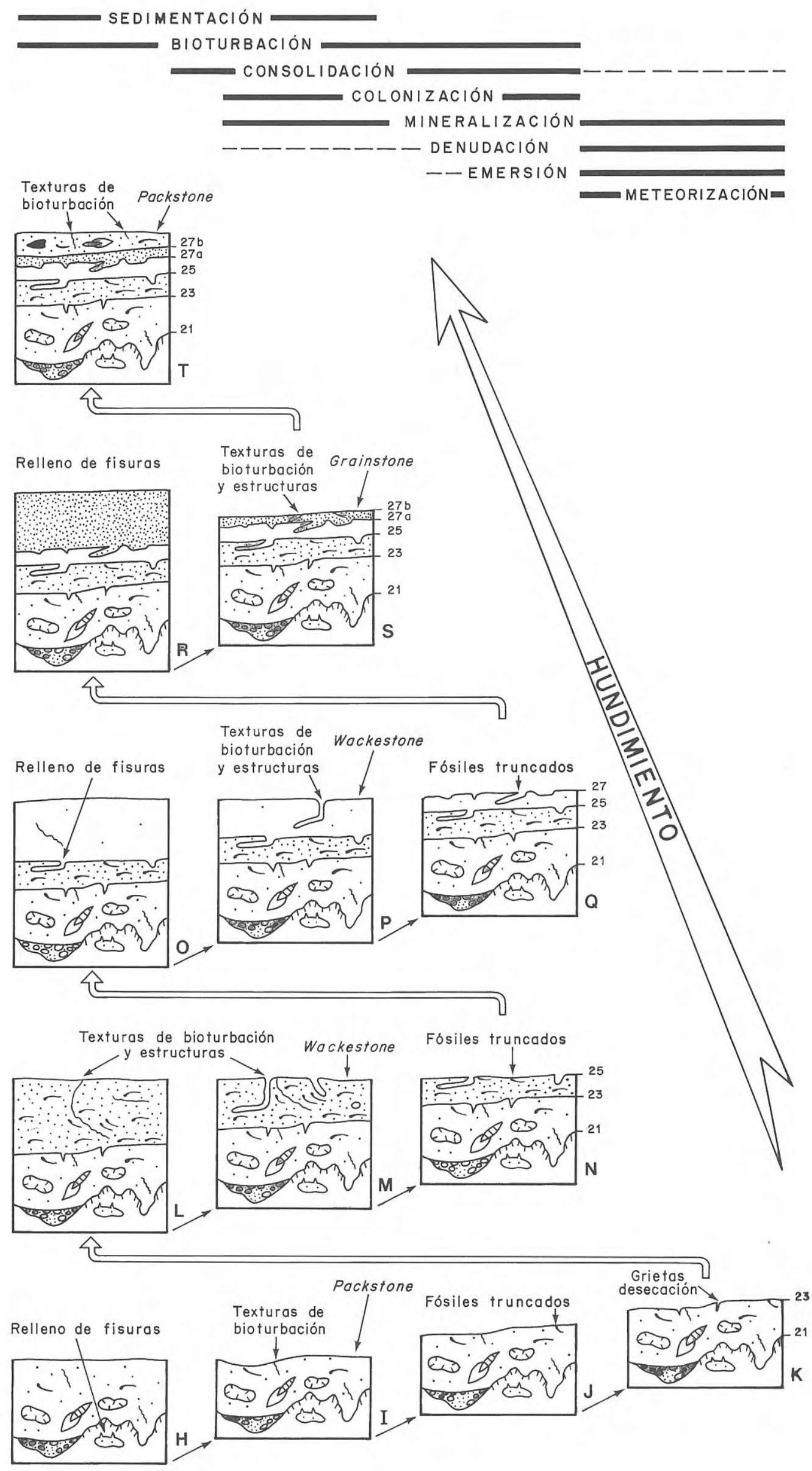




\section{SECCIONES CONDENSADAS PROXIMALES - DISTALES}

\begin{abstract}
SEDIMENTOS ......... dilatados - condensados CONDENSACIÓN TAFONÓMICA . . . . . . máxima - mínima HERENCIA TAFONÓMICA . . . . . . . . . . alta - moderada GRADO DE EMPAQUETAMIENTO . . . . . . . . . . . bajo - alto

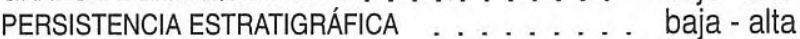
POBLACIONES TAFÓNICAS TIPO $1 \ldots$. . ausentes - presentes AMMONITES HUECOS ......... abundantes - escasos AMMONITES REELABORADOS . . redondeados - angulosos PERFORACIONES BIOGÉNICAS . . . . . . abundantes - escasas AMMONITES PIRITOSOS . . . . . . . escasos - frecuentes LAGUNAS BIOESTRATIGRÁFICAS . . . . f frecuentes - escasas
\end{abstract}

Tabla 1. Caracteres diferenciales de las secciones condensadas de áreas proximales de plataforma carbonática respecto a las secciones de áreas distales.

de grano en la base de la parasecuencia (cf. Arnott, 1995).

Los sistemas deposicionales se acuñan y desaparecen rápidamente hacia las áreas proximales, pero los moldes internos concrecionales de ammonites formados durante esas fases pueden ser incorporados en los ulteriores sistemas deposicionales progradacionales de alto nivel, incluso como asociaciones condensadas con moldes concrecionales completos. Ésta es la causa de los grados de condensación tan altos que pueden llegar a alcanzar las asociaciones registradas de ammonites en las plataformas epicontinentales carbonáticas más someras, incluso cuando dichas asociaciones están constituidas por elementos completos que fueron incluidos en calizas de tipo mudstone durante episodios de máxima tasa de sedimentación. Para interpretar estos procesos de condensación tafonómica en las plataformas epicontinentales carbonáticas es necesario tener en cuenta la duración relativa de los procesos de acumulación, resedimentación y reelaboración tafonómica (Fig. 1). En el caso de los ammonites, la acumulación de las conchas en los fondos marinos profundos pudo ser prácticamente inmediata a la muerte del organismo. Sin embargo, la acumulación de las conchas de ammonites en las plataformas epicontinentales carbonáticas pudo tardar incluso varios meses (Fernández-López, 1987a, 1997). Las conchas resedimentadas pudieron permanecer sobre el fondo marino decenas de años. Algunos moldes internos concrecionales de las conchas de ammonites pudieron permanecer sobre el fondo marino, después de ser exhumados y antes de su enterramiento final, durante más de una decena de millones de años. Los ejemplares de ammonites sometidos a procesos de reelaboración de este tipo son frecuentes en los materiales del Jurásico Medio de las plataformas Castellana, Aragonesa y de Tortosa (Fernández-López, 1985a; Fernández-López et al., 1996).

Las secciones condensadas de las secuencias deposicionales de tercer orden presentan caracteres diferenciales en las áreas proximales respecto a las distales (Tabla 1). Las asociaciones registradas de ammonites formadas en las plataformas epicontinentales someras alcanzan valores de condensación tafonómica más altos que las formadas en los fondos marinos profundos, aunque el grado de herencia tafonómica (proporción de elementos reelaborados) que presentan puede llegar a ser del $100 \%$ en ambos casos (FernándezLópez, 1997). El grado de empaquetamiento de los restos de ammonites (estimado por el valor de la diferencia entre el número de ejemplares y el número de niveles fosilíferos respecto al número de niveles fosilíferos) y su persistencia estratigráfica (proporción de niveles fosilíferos) tienen valores menores en las secciones proximales que en las distales. Las secciones condensadas de áreas distales contienen poblaciones tafónicas de tipo 1, cuyos elementos suelen tener el fragmocono relleno de sedimento y presentan superficies de desarticulación o de fractura con márgenes agudos, sin señales acusadas de rodamiento y con valores bajos de redondez, siendo localmente frecuentes los ammonites piritosos; en cambio, en las áreas proximales, las poblaciones tafónicas de tipo 1 no están representadas, los ammonites huecos (sin relleno sedimentario en el fragmocono) son abundantes, los moldes internos reelaborados presentan señales de rodamiento y valores altos de redondez, además de abundantes perforaciones biogénicas, y los ammonites piritosos son escasos (Fernández-López, 1997). Las sucesiones estratigráficas de las plataformas epicontinentales someras presentan mayor proporción de lagunas bioestratigráficas que las sucesiones formadas en los fondos marinos profundos (cf. Sadler, 1981; Schindel, 1982; McKinney, 1985; Tipper, 1987; Kowalewski, 1996). Sin embargo, la proporción de lagunas bioestratigráficas puede llegar a ser mayor que la proporción de lagunas registráticas en las secciones condensadas de plataforma somera, donde el registro fósil es más completo que el registro estratigráfico.

\section{CICLOS SEDIMENTARIOS TRANSGRESIVO/REGRESIVOS}

Los llamados ciclos sedimentarios transgresivo/regresivos de tercer orden representan variaciones a largo plazo, del orden de varios millones de años (con un rango comprendido entre 0,5 y 5 Ma, según Vail et al., 1991 y Jacquin et al., 1992; entre 0,5 y $3 \mathrm{Ma}$, con una duración media de 0,8 Ma para el Mesozoico, según Einsele, 1992; Homewood et al., 1992; Graciansky et al., 1993; Vera Torres, 1994 y Jacquin \& Vail, 1995; entre 1 y $10 \mathrm{Ma}$, según Miall, 1995; de 1 Ma, según Fels, 1995; entre 1,5 y 2,5 Ma, en Reboulet, 1995; entre 1 y 5 Ma, en Rousselle, 1997). Los ciclos sedimentarios transgresivo/regresivos de tercer orden pueden comprender una o más secuencias deposicionales de tercer orden.

Teniendo en cuenta los cambios relativos del potencial de acomodación y de la tasa de producción de sedimentos de las plataformas epicontinentales carbonáticas, durante el desarrollo de los ciclos ambientales de profundización/somerización de tercer orden es posible distinguir seis fases sucesivas (Fig. 9): 


\section{CICLO AMBIENTAL DE PROFUNDIZACIÓN-SOMERIZACIÓN DE TERCER ORDEN}

CICLO SEDIMENTARIO

TRANSGRESIVO-REGRESIVO

DE TERCER ORDEN

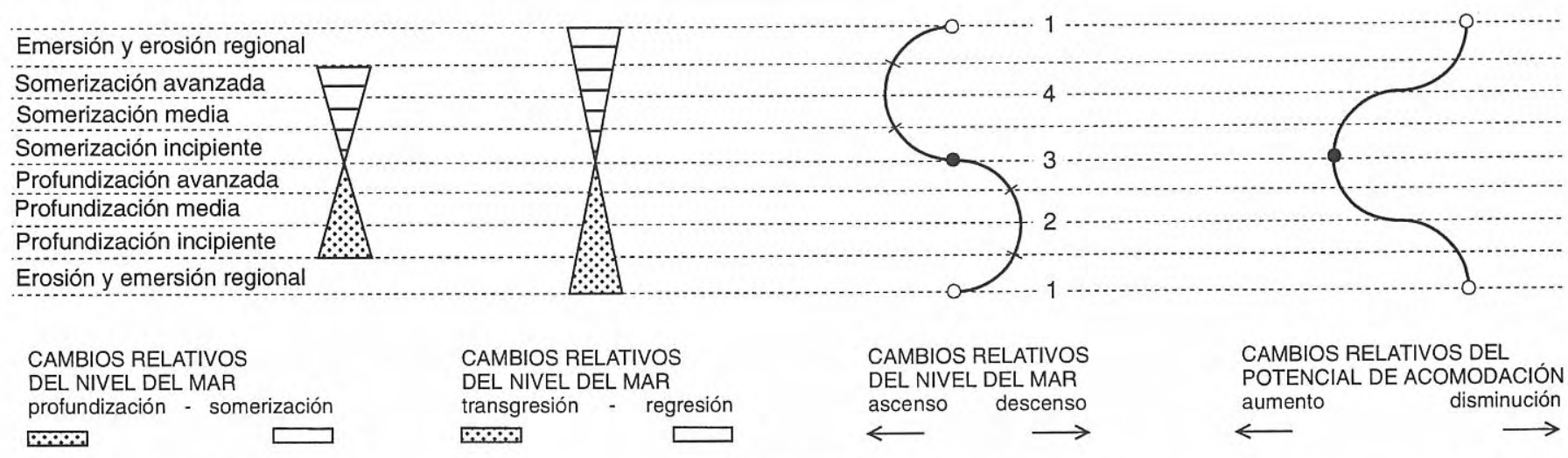

Figura 9. Los cambios relativos del potencial de acomodación (i.e., subsidencia más eustasia) y las variaciones en las tasas de cambio relativo del nivel del mar, dos conceptos fundamentales de la estratigrafía secuencial, han condicionado el desarrollo no sólo de ciclos sedimentarios transgresivo/regresivos sino también de ciclos ambientales de profundización/somerización en las plataformas epicontinentales carbonáticas. La curva que representa los cambios relativos del nivel del mar durante el desarrollo de los ciclos sedimentarios transgresivo/regresivos de tercer orden suele ser subdividida en cuatro partes para diferenciar cuatro fases sucesivas: 1) descenso rápido; 2) tasa de ascenso creciente; 3) ascenso rápido; 4) tasa de ascenso decreciente. En un ciclo ambiental de profundización/somerización se pueden distinguir seis fases sucesivas, desde la fase de profundización incipiente hasta la de somerización avanzada.

1) Fase de profundización incipiente: cuando los ambientes marinos abiertos sólo ocupan las áreas distales o más deprimidas de la plataforma y comienza a aumentar el espacio de acomodación y la producción de carbonatos, después de una fase de emersión y erosión regional.

2) Fase de profundización media: los ambientes marinos abiertos ocupan áreas cada vez más proximales y elevadas de la plataforma externa.

3) Fase de profundización avanzada: las tasas de producción de sedimentos son insuficientes respecto al espacio de acomodación que se genera en la plataforma, por lo cual retrogradan los ambientes deposicionales.

4) Fase de somerización incipiente: la tasa de producción de sedimentos aumenta más rápidamente que el espacio de acomodación y las tasas de sedimentación aumentan en las áreas más profundas.

5) Fase de somerización media: los ambientes marinos abiertos ocupan áreas cada vez más distales y deprimidas de la plataforma externa.

6) Fase de somerización avanzada: los ambientes marinos abiertos sólo ocupan las áreas más distales o deprimidas de la plataforma, donde disminuye el espacio de acomodación y la producción de carbonatos, mientras que las áreas proximales o elevadas de la plataforma experimentan procesos de emersión y erosión.

Los ciclos sedimentarios transgresivo/regresivos de tercer orden comprenden variaciones relativas y cíclicas del nivel del mar. Sin embargo, los ciclos ambientales de profundización/somerización de tercer orden, que también inducen variaciones cíclicas del potencial de acomodación de los sedimentos, pueden ser el resultado exclusivamente de variaciones cíclicas de la subsidencia. Por otra parte, una alta producción de sedimentos puede llegar a ocupar todo el espacio disponible generado por ascenso relativo del nivel del mar, dando lugar a una fase de somerización y emersión incluso durante una fase transgresiva (Wilgus et al., 1988; Jacquin y Vail, 1995). Por tanto, las fases transgresivas o regresivas no pueden ser identificadas simplemente por las evidencias de profundización o de somerización, y es necesario tener en cuenta las relaciones espacio-temporales entre los distintos ambientes desarrollados. Los ambientes marinos abiertos ocupan áreas más costeras y proximales de las plataformas durante las fases transgresivas, y áreas cada vez más externas y distales durante las fases regresivas. En consecuencia, los ciclos ambientales transgresivo/regresivos pueden ser inferidos teniendo en cuenta las relaciones espacio-temporales entre los distintos ambientes que componen los ciclos de profundización/somerización. La identificación de ciclos ambientales de profundización/somerización es de máxima importancia para la interpretación de los ciclos transgresivo/regresivos de las plataformas epicontinentales carbonáticas cuando no hay evidencias de las modificaciones de la línea de costa y los ambientes de plataforma externa están ampliamente desarrollados, como ocurre a menudo en las plataformas europeas del Jurásico Medio.

Los cambios relativos del nivel del mar que fueron consecuencia de los movimientos eustáticos y/o de la subsidencia dieron lugar a ciclos tafonómicos particulares, a tafociclos de profundización/somerización, en las plataformas epicontinentales carbonáticas. Las asociaciones registradas de ammonites formadas en 
distintas fases de estos ciclos ambientales de profundización/somerización presentan diferentes caracteres secundarios y constituyen distintos taforregistros (cf. Fernández-López, 1987b; 1995). Las sucesivas asociaciones registradas de ammonites que constituyen un tafociclo ideal de profundización/ somerización en las plataformas epicontinentales carbonáticas pueden ser agrupadas con criterios tafonómicos en taforregistros sucesivos de distintas categorías: taforregistros de profundización incipiente, media y avanzada, así como taforregistros de somerización incipiente, media y avanzada.

\section{Límites entre sucesivos tafociclos de profundización/ somerización}

El primer paso para identificar en las plataformas epicontinentales carbonáticas los sucesivos tafociclos de profundización/somerización consiste en determinar las lagunas registráticas de extensión regional, las lagunas del registro fósil que afectan incluso a las áreas más distales y profundas de la plataforma externa (Fig. 10). Los episodios de registro fósil sin registro estratigráfico son frecuentes en las plataformas epicontinentales carbonáticas durante las fases de emersión y erosión regional. Por este motivo, las lagunas registráticas identificadas con ammonites suelen tener menor amplitud geocronológica que las lagunas estratigráficas contemporáneas y permiten diagnosticar con mayor precisión los episodios de emersión que han afectado a las plataformas mesozoicas.

Las tasas de sedimentación en las áreas de plataforma externa disminuyen y algunos de los ambientes deposicionales previamente sumergidos pueden quedar emergidos durante las etapas de descenso relativo rápido del nivel del mar, al mismo tiempo que se interrumpen los procesos de sedimentación y los de acumulación de restos de ammonites en estas áreas de la plataforma. La prolongada exposición subaérea y la intensa diagénesis temprana provocan la modificación de los sedimentos y de los elementos conservados que contienen. Las modificaciones tafonómicas más frecuentes se deben a procesos de reelaboración, abrasión y disolución. Las tasas de sedimentación son nulas en estas áreas emergidas, y predominan los substratos endurecidos o los substratos rocosos. Estas condiciones se desarrollaron en la Plataforma Castellana, en la Plataforma Aragonesa y en la Plataforma de Tortosa durante el Biocrón Murchisonae (Aaleniense), al final del Biocrón Parkinsoni (Bajociense), durante el Biocrón Discus (Bathoniense) y durante los Biocronos Lamberti y Mariae (tránsito Calloviense/Oxfordiense), dando lugar a sendas lagunas estratigráficas de extensión regional en la Cuenca Ibérica (Fernández-López, 1980, 1985a, b, c; Aurell, 1990; Fernández-López y Gómez, 1990a, b, 1991; Meléndez et al., 1990; Aurell et al., 1995; Ramajo y Meléndez, 1996).

Los procesos de biodegradación-descomposición y disolución de los escasos restos de ammonites que pueden llegar hasta algunas de las áreas de plataforma externa que han quedado emergidas, por ejemplo durante

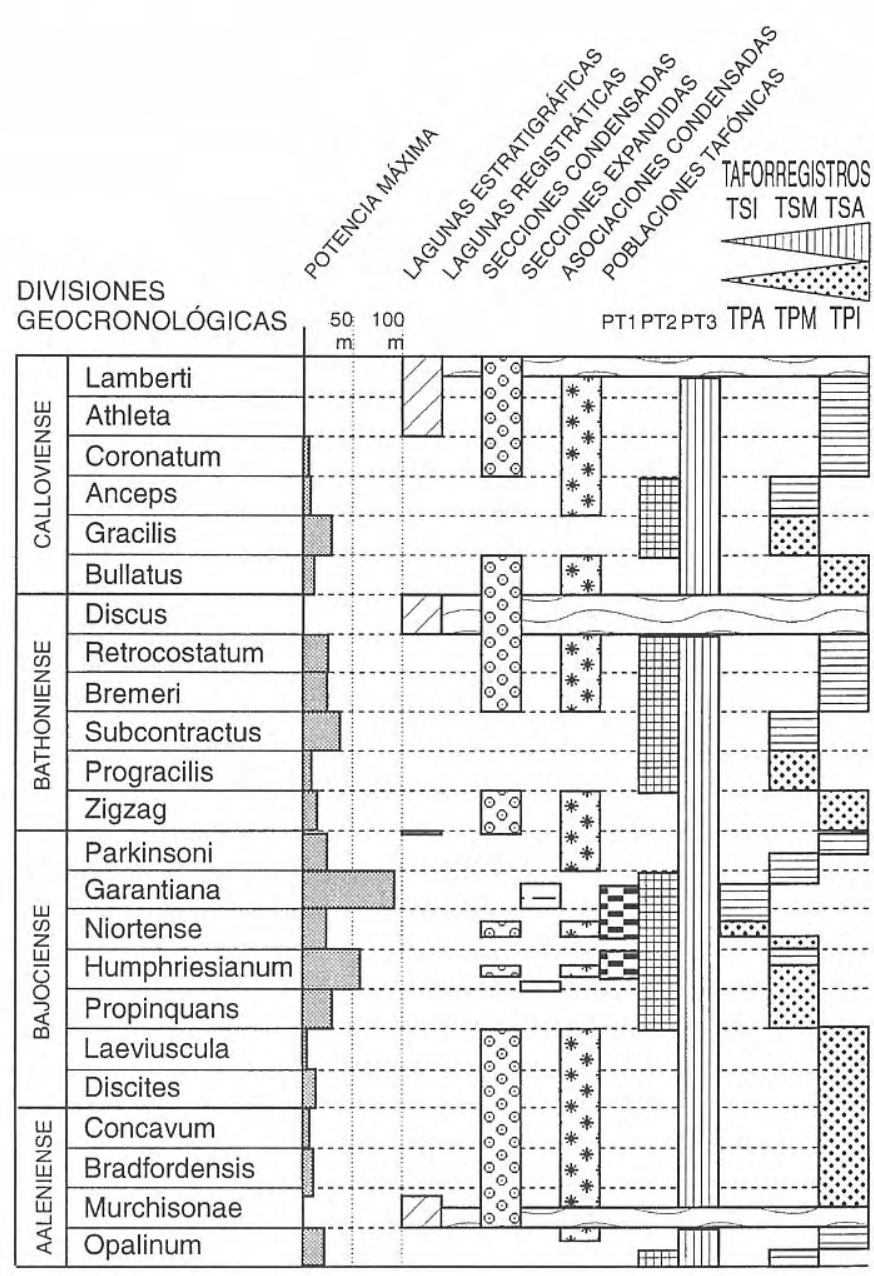

Figura 10. Diagrama a escala zonal de las variaciones de potencia máxima, distribución de lagunas, secciones condensadas o expandidas, asociaciones condensadas, tipos de poblaciones tafónicas y taforregistros de ammonites identificados en el Jurásico Medio de las plataformas Castellana, Aragonesa y de Tortosa. $\mathrm{PT} 1=$ poblaciones tafónicas de tipo 1 . PT2= poblaciones tafónicas de tipo 2. PT3= poblaciones tafónicas de tipo 3. TPI= taforregistro de profundización incipiente. TPM $=$ taforregistro de profundización media. $\mathrm{TPA}=$ taforregistro de profundización avanzada. TSI = taforregistro de somerización incipiente. TSA $=$ taforregistro de somerización media. $\mathrm{TSA}=$ taforregistro de somerización avanzada.

las tempestades, son muy intensos y rápidos. Las conchas carecen de partes blandas en la cámara de habitación y suelen ser rápidamente disueltas en estas áreas. Excepcionalmente se pueden formar moldes internos parciales de las cámaras de habitación, indicativos de tasas de acumulación de sedimentos muy altas. En estas condiciones tienen lugar procesos de reelaboración de moldes concrecionales cementados en fases anteriores, y los elementos reelaborados adquieren señales de disolución y complejos rellenos debidos a concentración de residuos insolubles y múltiples fases de relleno 
sedimentario separadas por fases de cementación. Algunos de estos rellenos son siliciclásticos y afectan a elementos no desplazados ni desenterrados, dando lugar a pseudomorfosis siliciclásticas. Durante la reelaboración, los moldes internos concrecionales tienden a reagruparse, a menudo se disponen de manera imbricada o en posición vertical, se pueden formar moldes concrecionales sin septos, y los moldes adquieren facetas de truncamiento y de rodamiento, por abrasión, así como superficies de desarticulación y de fractura.

Una vez identificadas las sucesivas lagunas registráticas de extensión regional, se procede a identificar los intervalos temporales que están representados por secciones condensadas o por secciones expandidas, y los intervalos de formación de asociaciones condensadas (Fig. 10). Otro de los criterios más significativos para interpretar los ciclos ambientales de profundización/somerización es la distribución de las distintas poblaciones tafónicas de ammonites. Cuando las asociaciones condensadas contienen mayor número de poblaciones tafónicas de tipo 1 (PT1) representan ambientes de profundización avanzada; en caso contrario, si sólo están constituidas por poblaciones tafónicas de tipo 3 (PT3) pueden corresponder a ambientes de profundización incipiente o de somerización avanzada.

Durante las etapas de profundización de las plataformas epicontinentales carbonáticas pueden desarrollarse uno o más taforregistros de profundización dependiendo de las condiciones ambientales y de la tasa de ascenso relativo del nivel del mar. Los taforregistros de profundización desarrollados en las porciones más distales de la plataforma suelen presentar caracteres secundarios más variados que los formados en las áreas más someras y proximales, desde los estadios iniciales de profundización incipiente hasta los estadios finales de profundización avanzada (Fig. 11). Simultáneamente, en las áreas proximales y menos profundas de las plataformas epicontinentales carbonáticas, sólo se desarrollan taforregistros de profundización media y avanzada durante el mismo intervalo temporal.

Los taforregistros de somerización están constituidos por asociaciones registradas topológicamente sucesivas respecto a las que constituyen los taforregistros de profundización del mismo ciclo. Su mayor desarrollo lo alcanzan en las porciones más distales de la plataforma, donde ha quedado registro del cambio ambiental desde los estadios iniciales de somerización incipiente hasta los estadios finales de somerización avanzada. En las porciones proximales y menos profundas de las plataformas, sólo se desarrollan taforregistros de somerización incipiente y media durante el mismo intervalo temporal.

\section{Taforregistros de profundización incipiente}

Los taforregistros de profundización incipiente representan el primer estadio de los tafociclos de profundización/somerización. Se generan en las áreas distales o más deprimidas de la plataforma externa, cuando comienza a aumentar el espacio de acomodación y la producción de carbonatos, después de una fase de

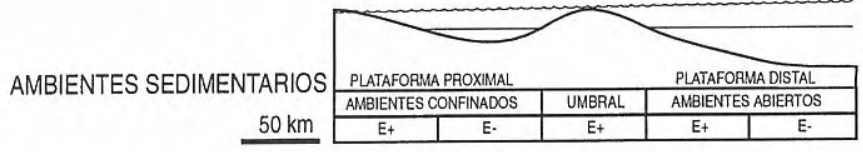

\section{TAFOCICLO DE PROFUNDIZACIÓN/SOMERIZACIÓN:}

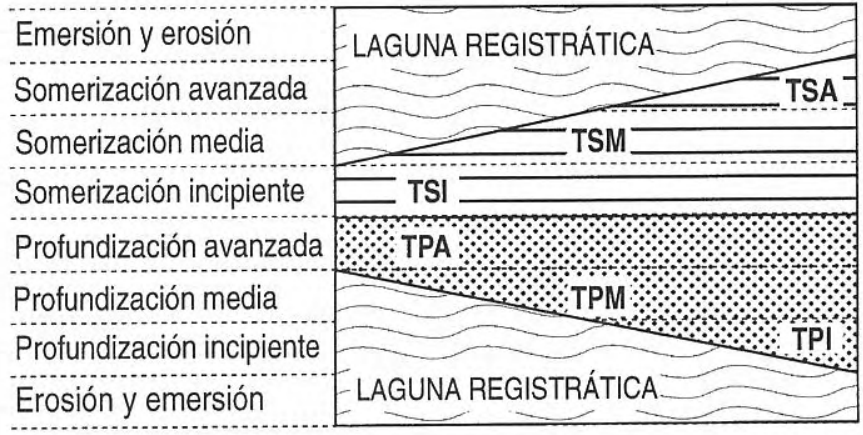

Figura 11. Los taforregistros de ammonites desarrollados en las plataformas epicontinentales carbonáticas durante un tafociclo de profundización/somerización presentan caracteres más variados en las áreas distales y deprimidas que en las áreas proximales y someras. Los taforregistros de profundización incipiente (TPI) y los de somerización avanzada (TSA) sólo se desarrollaron en las áreas distales de la plataforma. TPI $=$ taforregistro de profundización incipiente. TPM= taforregistro de profundización media. TPA $=$ taforregistro de profundización avanzada. $\mathrm{TSI}=$ taforregistro de somerización incipiente. TSA $=$ taforregistro de somerización media. TSA = taforregistro de somerización avanzada.

emersión y erosión regional. Los sedimentos son rápidamente cementados y predominan los substratos estables, que suelen presentar señales de desecación y meteorización local. Las tasas de sedimentación suelen ser muy bajas, pero están asociadas a tasas de acumulación de sedimentos muy variables. Simultáneamente, en las áreas proximales de la plataforma externa, continúan desarrollándose una laguna estratigráfica y una laguna registrática. Estas condiciones paleogeográficas se desarrollaron en la Plataforma Castellana, en la Plataforma Aragonesa y en la Plataforma de Tortosa durante los biocronos Bradfordensis, Concavum, Discites y Laeviuscula (Aaleniense-Bajociense; Fernández-López, 1985c; Fernández-López y Gómez, 1990a, b, 1991; FernándezLópez et al., 1996), así como durante el Biocrón Zigzag (Bathoniense inferior; Fernández-López et al., 1978, 1988; Fernández-López y Aurell, 1988; Lardiés, 1990; Fernández-López et al., 1996) y durante el Biocrón Bullatus (Calloviense inferior; Sequeiros y Meléndez, 1987; Aurell et al., 1990).

Después de una fase de emersión regional y cuando el descenso relativo del nivel del mar en la plataforma externa llega a ser mínimo o nulo, las conchas de ammonites todavía pueden acumularse en las áreas más 
distales o deprimidas, pero suelen ser rápidamente resedimentadas (Fig. 12). La importación de conchas por deriva necroplanctónica suele ser baja, aunque localmente puede haber altas concentraciones. Predominan las poblaciones tafónicas de tipo 3 , resedimentadas o reelaboradas. Según las áreas, las asociaciones conservadas de ammonites tienen valores muy variables de grado de empaquetamiento (estimado por el valor de la diferencia entre el número de ejemplares y el número de niveles fosilíferos respecto al número de niveles fosilíferos). Las asociaciones de ammonites se caracterizan por tener valores muy bajos de persistencia estratigráfica (proporción de niveles estratigráficos con restos de ammonites) y escasa continuidad lateral. Los procesos bioestratinómicos de biodegradación-descomposición fueron intensos. Las conchas suelen carecer de partes blandas y de apticus en la cámara de habitación, así como de periostraco, y de anillos conectivos en el sifón. El tubo sifonal suele estar totalmente desarticulado. Entre las conchas resedimentadas y enterradas son frecuentes los fragmoconos sin relleno sedimentario, indicativos de procesos de relleno sedimentario muy rápidos y tasas de acumulación de sedimentos altas, y los ammonites huecos, que conservan su volumen y forma como consecuencia de la rápida cementación temprana. Las conchas pueden presentar encostramientos microbianos, desarrollados durante la resedimentación, y restos esqueléticos de organismos colonizadores muy diversos, indicativos de procesos de deriva necroplanctónica intensos y duraderos. Sobre las conchas resedimentadas y sobre los moldes reelaborados se desarrollan láminas estromatolíticas calcáreas, a veces fosfáticas y/o ferruginosas. Los moldes reelaborados pueden presentar facetas de rodamiento y facetas de truncamiento; a veces, y asociados a substratos duros y homogéneos, presentan facetas elipsoidales de desgaste o surcos anulares. Es frecuente que los elementos conservados estén reorientados y reagrupados, formando agrupamientos encajados o imbricados, incluso cuando están incluidos en depósitos de facies canalizadas o formados por eventos locales de turbulencia. En estas condiciones ambientales se forman tafosecuencias positivas acusadas. Las asociaciones condensadas que se encuentran en la base de las parasecuencias suelen presentar valores altos de condensación tafonómica, y algunos de sus elementos muestran evidencias de exposición subaérea, erosión y transporte, e incluso pueden ser más antiguos que los sedimentos del techo de la parasecuencia anterior.

\section{Taforregistros de profundización media}

Los taforregistros de profundización media se forman en la plataforma externa cuando hay aguas marinas oxigenadas y la tasa de ascenso relativo del nivel del mar es suficientemente lenta como para permitir que aumente la producción de carbonatos al aumentar el espacio de acomodación. Estas condiciones promueven el desarrollo de bioconstrucciones y dificultan los procesos de acreción lateral. Esta fase de profundización suele coincidir con la fase de agradación de los ciclos sedimentarios de tercer orden (cf. Jacquin y Vail, 1995). Las tasas de acumulación de sedimentos suelen ser altas, aunque las tasas de sedimentación pueden ser muy variables en las distintas áreas. En función de la morfología del fondo marino, la plataforma externa puede tener condiciones restringidas en las áreas proximales o condiciones de mar abierto generalizadas. La turbulencia tiende a ser menor, al disminuir la acción del oleaje y el efecto de las tormentas sobre el fondo marino. Estas condiciones paleogeográficas se desarrollaron en la Plataforma Castellana, en la Plataforma Aragonesa y en la Plataforma de Tortosa durante los biocronos Propinquans, Humphriesianum y Niortense (Bajociense; Fernández-López, 1985c; Fernández-López y Mouterde, 1985; Fernández-López et al., 1996), así como durante los biocronos Progracilis (Bathoniense; Fernández-López et al., 1978; Lardiés, 1990) y Gracilis (Calloviense inferior; Sequeiros y Meléndez, 1987).

Las asociaciones conservadas de ammonites pueden llegar a ocupar las áreas más proximales y someras de la plataforma externa, al aumentar lentamente el nivel relativo del mar hasta alcanzar varias decenas de metros de profundidad en las áreas distales. La importación de conchas derivadas suele ser alta, debido al aumento del espacio de acomodación. Predominan las poblaciones tafónicas de tipo 3 y 2 . Los patrones de distribución de las conchas suelen ser agrupados, y tanto el grado de empaquetamiento como la persistencia estratigráfica de las asociaciones registradas de ammonites suelen ser muy variables según las áreas. El grado de herencia tafonómica y el grado de removilización de las sucesivas asociaciones de ammonites disminuyen rápidamente cuando la tasa de producción de sedimentos sobrepasa la tasa de ascenso relativo del nivel del mar, pero estos índices no presentan variaciones significativas si la tasa de producción de sedimentos coincide con la tasa de ascenso relativo del nivel del mar. Las tafosecuencias positivas pasan a ser menos acusadas cuando aumenta la tasa de sedimentación y más acusadas cuando disminuye. En las áreas proximales todavía se pueden generar asociaciones condensadas con evidencias de exposición subaérea, coincidiendo con los límites de las parasecuencias.

En los ambientes abiertos, las tasas de acumulación de sedimentos suelen ser altas, pero las tasas de sedimentación son muy variables de unas áreas a otras. Las conchas acumuladas son escasas, y predominan las conchas resedimentadas. Localmente, coincidiendo con los límites de las parasecuencias, se forman moldes internos reelaborados, con facetas de rodamiento y de truncamiento. Los procesos bioestratinómicos de biodegradación-descomposición son menos intensos que en las fases de profundización incipiente o en las de profundización avanzada. Las conchas suelen carecer de partes blandas y de apticus en la cámara de habitación, pero pueden mantener el periostraco y los anillos conectivos durante la fase de enterramiento. Se suelen formar moldes internos parciales de las cámaras de habitación, indicativos de tasas de acumulación de sedimentos muy altas, y abundan los ammonites huecos. 


\section{TAFOCICLO DE PROFUNDIZACIÓN / SOMERIZACIÓN EN PLATAFORMAS EPICONTINENTALES CARBONÁTICAS}
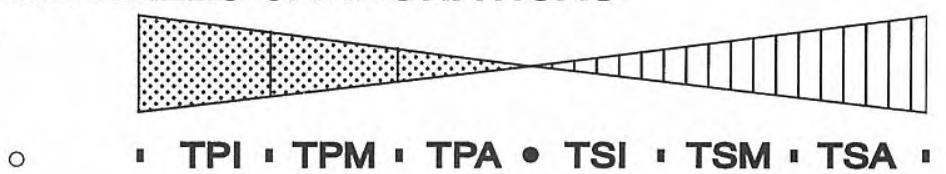

MECANISMOS DE ALTERACIÓN TAFONÓMICA y resultados:

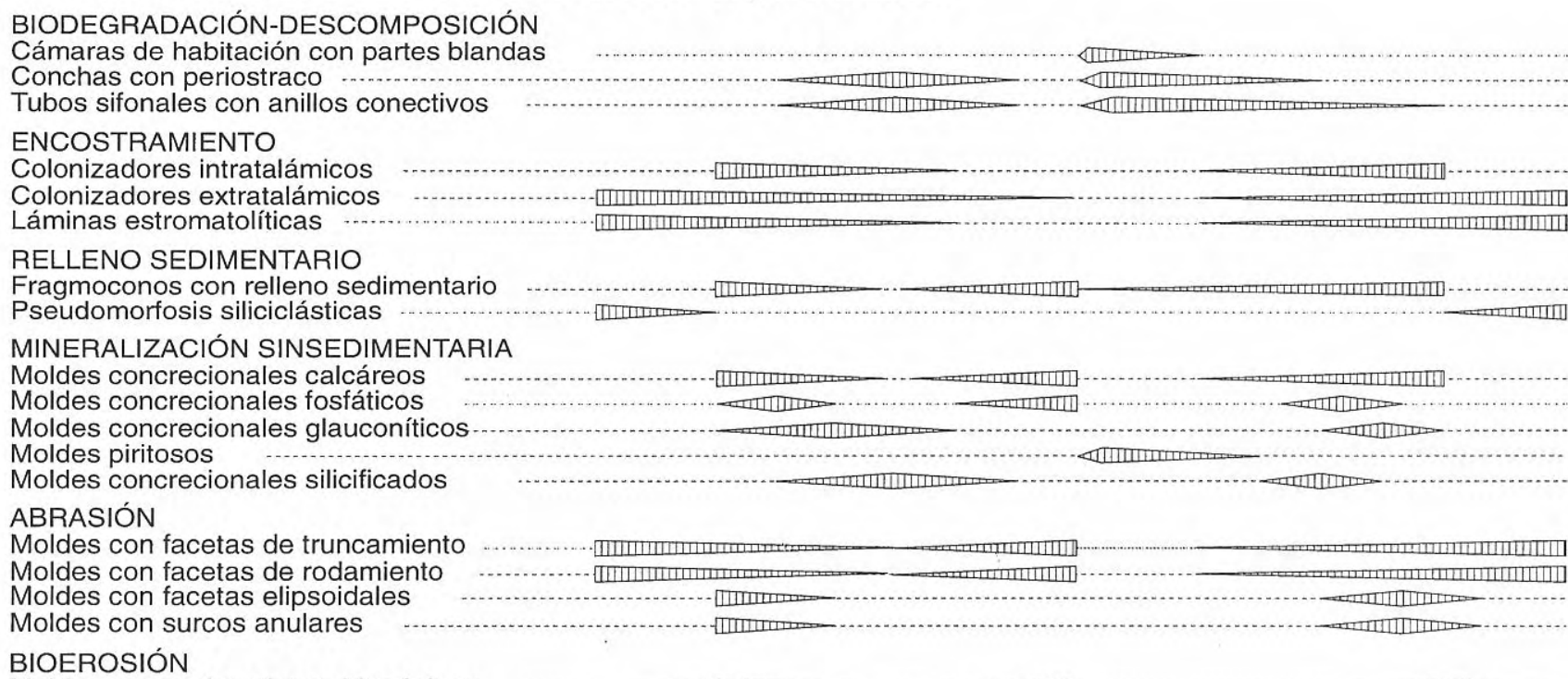

Moldes con perforaciones biogénicas

DISOLUCIÓN SINSEDIMENTARIA

Conchas sin septos (fragmoconos huecos) Periostracos sin septos ni muralla Moldes concrecionales sin septos

पाயس

DISTORSIÓN MECÁNICA

Conchas con fracturas abiertas y lobuladas Conchas con fracturas cerradas y enteras

Fragmoconos incompletos

Moldes fragmentados

Moldes con compactación discontinua

Moldes con compactación continua

REORIENTACIÓN

Conchas con orientación azimutal preferente

Moldes con orientación azimutal preferente

Conchas verticales

Moldes verticales

एய1

DESARTICULACIÓN

Apticus desarticulados

Conchas sin apticus

Sifón desarticulado

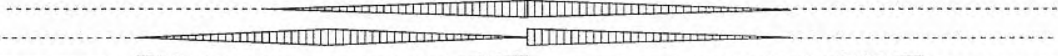

पणता

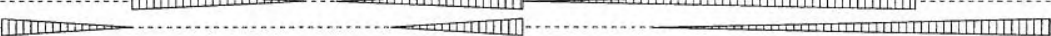

-

Moldes con superficies de desarticulación

DISPERSIÓN

Poblaciones tafónicas de tipo 1

Poblaciones tafónicas de tipo 2

Poblaciones tafónicas de tipo 3

REAGRUPAMIENTO

Conchas con agrupamiento encajado

Conchas con agrupamiento imbricado

Moldes con agrupamiento imbricado

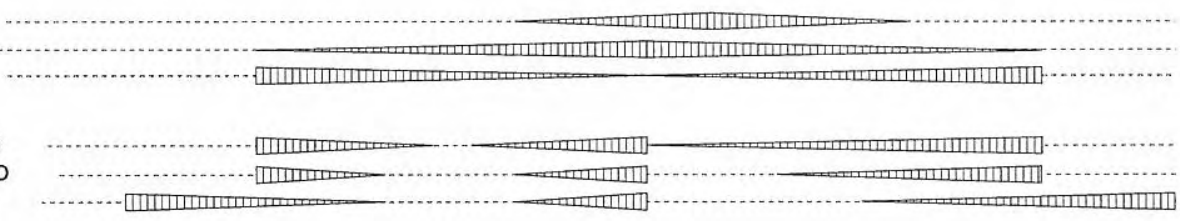

REMOVILIZACIÓN

Elementos acumulados

Elementos resedimentados

Elementos reelaborados

Figura 12. Características de los diferentes taforregistros de ammonites que constituyen un tafociclo de profundización/somerización en las plataformas epicontinentales carbonáticas. TPI= taforregistro de profundización incipiente. TPM= taforregistro de profundización media. TPA= taforregistro de profundización avanzada. TSI $=$ taforregistro de somerización incipiente. TSA $=$ taforregistro de somerización media. TSA= taforregistro de somerización avanzada. 
Sobre las conchas resedimentadas se pueden desarrollar organismos incrustantes, intratalámicos y extratalámicos. Sobre los moldes reelaborados se forman láminas estromatolíticas. Los moldes concrecionales pueden ser carbonáticos, fosfáticos o glauconíticos. Localmente, asociados a sedimentos formados en condiciones de alta tasa de acumulación pero baja tasa de sedimentación, se encuentran moldes concrecionales de sílex o silicificados.

En las áreas proximales suele haber condiciones restringidas. Las tasas de sedimentación y de acumulación de sedimentos generalmente son altas en los ambientes protegidos. Los fósiles reelaborados son muy escasos y están circunscritos a los límites entre parasecuencias. Las conchas acumuladas pueden llegar a ser frecuentes en las áreas de menor turbulencia. Los procesos bioestratinómicos de biodegradacióndescomposición pueden ser retardados por la escasez de oxígeno. Las conchas suelen carecen de partes blandas en la cámara de habitación, pero pueden tener todavía el periostraco y los anillos conectivos del sifón. El tubo sifonal suele estar articulado. Predominan los moldes internos parciales de las cámaras de habitación, indicativos de tasas de acumulación de sedimentos muy altas. Sobre las conchas resedimentadas y sobre los moldes reelaborados se forman láminas estromatolíticas. Los moldes concrecionales suelen ser carbonáticos. En los ambientes más confinados se pueden formar núcleos piritosos y puede haber conchas sin septos (fragmoconos huecos) por disolución temprana cerca de la interfase agua/sedimento.

\section{Taforregistros de profundización avanzada}

Los taforregistros de profundización avanzada caracterizan el último estadio de las fases de profundización desarrolladas en las plataformas epicontinentales carbonáticas. Adquieren su máximo desarrollo en las áreas más distales y profundas de la plataforma externa, donde predominan los ambientes oxigenados pero las tasas de producción de sedimentos son insuficientes respecto al espacio de acomodación que se está generando; por ello, disminuye la tasa de acumulación de los sedimentos y los ambientes deposicionales retrogradan. Las tasas de sedimentación y de acumulación de sedimentos suelen ser bajas. Las parasecuencias tienen un desarrollo menos claro que en las fases anteriores. Según el relieve del fondo marino pueden diferenciarse áreas elevadas y áreas deprimidas, pero no suele haber rupturas importantes o escarpes abruptos. Las variaciones laterales de las condiciones ambientales tienden a ser graduales. El fondo de la plataforma externa permanece por debajo del nivel de base del oleaje e incluso del de las tormentas, durante estos episodios de máxima profundización. Estas condiciones paleogeográficas se desarrollaron en la Plataforma Castellana, en la Plataforma Aragonesa y en la Plataforma de Tortosa durante el Biocrón Niortense (Subcronozona Polygyralis, Bajociense Superior; Fernández-López, 1985c; Fernández-López et al., 1996).

La plataforma externa constituye una rampa carbonática cuya máxima profundidad puede variar desde unas decenas hasta un centenar de metros, durante esta fase de profundización. Los episodios finales de esta fase de profundización corresponden a los estadios de máxima profundización. Aunque la concentración de conchas de ammonites suele ser menor que en la fase anterior, se producen poblaciones tafónicas de tipo 1,2 y 3 . La presencia de poblaciones tafónicas de tipo 1 es indicativa de producción biogénica autóctona, sin señales de selección o clasificación por necrocinesis. Las asociaciones de ammonites suelen presentar valores relativamente bajos de grado de empaquetamiento, pero relativamente altos de persistencia estratigráfica. Los procesos bioestratinómicos de biodegradacióndescomposición son intensos. Las conchas carecen de partes blandas, apticus y periostraco antes de ser enterradas. El tubo sifonal suele estar desarticulado. Los incrustantes intratalámicos o extratalámicos aparecen preferentemente desarrollados en los elementos conservados de las poblaciones tafónicas de tipo 2 ó 3. El grado de removilización y el grado de herencia tafonómica adquieren valores relativamente altos. Se suelen formar moldes internos concrecionales de la cámara de habitación y del fragmocono, indicativos de bajas tasas de acumulación de sedimentos. Son frecuentes los niveles de removilización, con moldes concrecionales carbonáticos o fosfáticos. Sólo localmente se forman núcleos piritosos. Los moldes reelaborados suelen presentar superficies de desarticulación con márgenes agudos, y pueden aparecer moldes concrecionales fragmentados, pero sin señales acusadas de rodamiento, encostramiento o bioerosión, como consecuencia del bajo grado de turbulencia del ambiente externo. No obstante, localmente, los moldes y las conchas pueden estar reagrupados de manera imbricada o presentar orientación azimutal preferente. Durante las etapas con predominio de sedimentación de fondo, se forman asociaciones granocrecientes en sedimentos de grano fino sin discontinuidades aparentes, en tanto que los eventos de turbulencia dan lugar a asociaciones granodecrecientes incluidas en sedimentos de mayor tamaño de grano y de base erosiva (Fernández-López, 1997, fig. 15).

\section{Taforregistros de somerización incipiente}

Los taforregistros de somerización incipiente representan el primer estadio de las fases de somerización desarrolladas en las plataformas epicontinentales carbonáticas. En estas condiciones de gran profundidad, el fondo de la plataforma externa puede permanecer por debajo del nivel de base del oleaje e incluso de las tormentas. Los primeros depósitos tienen amplia distribución geográfica, son agradacionales o de escasa progradación. Al aumentar el suministro de terrígenos finos, aumentan rápidamente las tasas de sedimentación y se forman secciones margosas y expandidas. Las tasas de sedimentación son altas en las áreas más profundas, pero las tasas de acumulación de sedimentos pueden ser muy variables. Estas condiciones se desarrollaron en la Plataforma Castellana, en la Plataforma Aragonesa y en 1a Plataforma de Tortosa durante los biocronos Humphriesianum, Niortense y Garantiana (subcrono- 
zonas Blagdeni, Baculata, Dichotoma y Subgaranti, Bajociense; Fernández-López, 1983, 1985c, 1986, 1987a; Fernández-López y Mouterde, 1985; Fernández-López et al., 1996; Fernández-López y Meléndez, 1995a, 1996). Los sedimentos de la Biozona Garantiana sobrepasan los 90 metros de espesor en la región de Tivenys (Plataforma de Tortosa).

Durante las fases de somerización incipiente, la plataforma externa totalmente inundada, con predominio de substratos blandos, constituye una rampa carbonática homogénea que suele sobrepasar varias decenas de metros de profundidad, con ambientes relativamente estables y variaciones graduales. Se forman poblaciones tafónicas de tipo 1, 2 y 3, con valores relativamente altos de grado de empaquetamiento y persistencia estratigráfica. La presencia poblaciones tafónicas de tipo 1 es indicativa de producción biogénica autóctona, sin señales de selección o clasificación por necrocinesis. En las áreas de mayor profundidad, las sucesivas asociaciones registradas pueden ser asociaciones expandidas (i.e., asociaciones registradas cuyos elementos estratigráficamente sucesivos representan organismos contemporáneos). Los procesos bioestratinómicos de biodegradación-descomposición pueden ser inhibidos por enterramiento rápido. Las conchas enterradas suelen carecer de relleno sedimentario en el fragmocono, son ammonites huecos, y pueden mantener partes blandas, el periostraco y los anillos conectivos. El tubo sifonal suele estar articulado. Los incrustantes intratalámicos o extratalámicos sólo están desarrollados sobre algunos elementos conservados de las poblaciones tafónicas de tipo 2 o 3. Por lo general, las poblaciones tafónicas de tipo 1 carecen de elementos con restos de incrustantes o láminas estromatolíticas en estas áreas distales de la plataforma. Los moldes internos pueden ser carbonáticos o piritosos, sólo en las áreas de menor tasa de sedimentación se forman moldes internos concrecionales carbonáticos durante la diagénesis temprana, pero los elementos reelaborados son muy escasos o están ausentes. Localmente son frecuentes las conchas acumuladas. El grado de removilización puede tener valores variables, pero el grado de herencia tafonómica es muy bajo o nulo. Las señales de abrasión o bioerosión son muy escasas, tanto en las conchas como en los moldes internos. Por disolución sinsedimentaria pueden desaparecer los tabiques y la muralla de las conchas, mientras permanece el periostraco, dando lugar a moldes comprimidos con deformaciones continuas por compactación diagenética gravitacional. Localmente son frecuentes los apticus desarticulados. Las conchas suelen estar dispersas en la matriz, sin formar agrupamientos imbricados o encajados. Las tafosecuencias están poco acusadas y las asociaciones de ammonites estratigráficamente sucesivas no suelen presentar variaciones acusadas en su estado de conservación.

Lateralmente, en las áreas someras, las sucesivas asociaciones registradas de ammonites pueden llegar a ser asociaciones condensadas. Los procesos bioestratinómicos de biodegradación-descomposición son más intensos. Los fragmoconos con relleno sedimentario y las señales de encostramiento son más frecuentes. Los moldes internos pueden ser carbonáticos, fosfáticos o glauconíticos, y los elementos reelaborados son cada vez más abundantes, en tanto que las conchas acumuladas son muy escasas. El grado de removilización y el grado de herencia tafonómica son cada vez más altos. Las señales de abrasión o bioerosión son frecuentes, tanto en las conchas como en los moldes internos. Por cementación temprana, los elementos conservados pueden mantener su volumen y forma, sin evidencias de compactación diagenética gravitacional. Localmente son frecuentes los apticus desarticulados. Las conchas y los moldes internos pueden formar agrupamientos imbricados o encajados. Las tafosecuencias están poco acusadas y las sucesivas asociaciones de ammonites suelen presentar estados de conservación muy semejantes entre sí.

\section{Taforregistros de somerización media}

Los ambientes de plataforma externa suelen tener menores tasas de sedimentación durante las fases de somerización media que durante las de somerización incipiente. Las cementaciones tempranas son frecuentes en las áreas proximales de la plataforma, aunque las tasas de acumulación de sedimentos son altas en las áreas distales. Los sistemas deposicionales son progradacionales o retrogradacionales, y de escaso espesor. Las facies con bioconstrucciones carbonáticas pueden desarrollarse también durante esta fase de somerización en los ambientes oxigenados y proximales, en tanto que las facies de microfilamentos suelen dominar en las áreas más distales y profundas. Las condiciones son cada vez de mayor turbulencia, al aumentar el efecto de las tormentas y la acción del oleaje. Estas condiciones paleogeográficas se desarrollaron en la Plataforma Castellana, en la Plataforma Aragonesa y en la Plataforma de Tortosa durante el Biocrón Opalinum (Aaleniense; FernándezLópez, 1985c; Fernández-López y Gómez, 1990a, b; Goy et al., 1994; Fernández-López et al., 1996), al final del Biocrón Garantiana y al principio del Biocrón Parkinsoni (subcronozonas Tetragona y Acris, Bajociense Superior; Fernández-López, 1985c, 1987a; Fernández-López y Mouterde, 1985; Fernández-López et al., 1996), así como al final del Bathoniense Medio (Fernández-López et al., 1978; Lardiés, 1990) y durante el Biocrón Anceps (Calloviense medio; Sequeiros y Meléndez, 1987; Aurell et al., 1990, 1995; Fernández-López et al., 1996).

En esta fase, en la que el nivel relativo del mar puede alcanzar unas decenas de metros de profundidad, todavía se pueden formar asociaciones registradas de ammonites en todas las áreas de la plataforma externa. La producción autóctona de conchas suele ser nula, pero la importación de conchas puede dar lugar a altas concentraciones locales. Predominan las poblaciones tafónicas de tipo 3 y 2. Los patrones de distribución de las conchas suelen ser agrupados. Las tasas de acumulación de sedimentos son altas, pero las tasas de sedimentación pueden ser muy variables de unas áreas a otras. Los moldes internos pueden ser calcáreos, fosfáticos o glauconíticos. Los elementos acumulados están prácticamente ausentes. Las tafosecuencias son más acusadas que en la fase anterior. 
En las áreas proximales se suelen formar asociaciones condensadas en la base de las tafosecuencias, que pueden ser positivas o negativas. El grado de removilización y de herencia tafonómica es cada vez mayor en las asociaciones más recientes y proximales. Los elementos acumulados están ausentes, y localmente predominan los elementos reelaborados, con facetas de truncamiento y de rodamiento. Los procesos bioestratinómicos de biodegradación-descomposición son intensos. Las conchas suelen carecer de partes blandas y de apticus en la cámara de habitación, así como de periostraco y anillos conectivos. Predominan los moldes internos parciales de las cámaras de habitación, como consecuencia de las altas tasas de acumulación de los sedimentos. Las conchas y los moldes internos suelen presentar restos de organismos cementantes, abundantes y diversos, así como láminas estromatolíticas. Los moldes concrecionales suelen ser carbonáticos, fosfáticos o glauconíticos. Localmente también se encuentran moldes concrecionales de sílex o silicificados.

\section{Taforregistros de somerización avanzada}

Los taforregistros de somerización avanzada representan el último estadio de los tafociclos de profundización/somerización. Se suelen formar en ambientes de baja tasa de sedimentación, donde son frecuentes los procesos de cementación temprana, aunque localmente en las áreas distales pueden acumularse abundantes mudstone que se caracterizan por una tasa relativamente alta de acumulación de sedimentos. En estas condiciones de sedimentación, se forman unidades progradacionales de escaso espesor en las áreas distales de la plataforma, que lateralmente hacia el continente pasan a inconformidades erosivas. Estas condiciones paleogeográficas se desarrollaron en la Plataforma Castellana, en la Plataforma Aragonesa y en la Plataforma de Tortosa al final del Biocrón Opalinum (Aaleniense; Fernández-López, 1985c; Fernández-López y Gómez, 1990a, b; Goy et al., 1994; Fernández-López et al., 1996), al final del Biocrón Parkinsoni (Subcronozona Bomfordi, Bajociense Superior; Fernández-López, 1985c, 1987a; Fernández-López et al., 1996), así como durante los biocronos Retrocostatum (Bathoniense; Fernández-López et al., 1978; Lardiés, 1990), Coronatum y Athleta (Calloviense; Gómez, 1979; Sequeiros et al., 1984; Fernández-López et al., 1985; Sequeiros y Meléndez, 1987; Meléndez, 1989; Aurell, 1990; Aurell et al., 1990, 1995; Lardiés, 1990; Fernández-López y Meléndez, 1995a, b, 1996; Fernández-López et al., 1996).

Cuando el ascenso relativo del nivel del mar llega a ser nulo o cuando comienza a descender el nivel relativo del mar, las asociaciones conservadas de ammonites pueden ocupar sólo las áreas más distales de la plataforma externa o bien áreas más amplias, dependiendo de la morfología del fondo marino. Predominan las poblaciones tafónicas de tipo 3, resedimentadas o reelaboradas. Los procesos bioestratinómicos de biodegradación-descomposición son intensos. Las conchas suelen carecer de partes blandas y de apticus en la cámara de habitación, así como de periostraco. El tubo sifonal suele estar desarticulado.

En las asociaciones registradas de las áreas distales, suelen dominar los elementos resedimentados con valores muy variables de grado de empaquetamiento y valores muy altos de persistencia estratigráfica. Predominan los moldes internos parciales de las cámaras de habitación, indicativos de procesos de relleno sedimentario muy rápidos y tasas de acumulación de sedimentos altas. También son frecuentes los ammonites huecos que conservan su volumen y forma, como consecuencia de la baja tasa de sedimentación y la rápida cementación temprana. Las conchas pueden presentar encostramientos microbianos desarrollados durante la resedimentación y restos esqueléticos de organismos colonizadores muy diversos, indicativos de procesos de deriva necroplanctónica intensos y duraderos. Las tafosecuencias positivas son muy acusadas. Los elementos reelaborados de las asociaciones condensadas que se encuentran en la base de las parasecuencias pueden presentar evidencias de exposición subaérea, erosión y transporte, e incluso ser más antiguos que los sedimentos del techo de la parasecuencia anterior.

Las asociaciones registradas de ammonites de las áreas más someras y proximales suelen ser asociaciones condensadas, locales y de escasa continuidad lateral. Las sucesivas asociaciones registradas suelen presentar variaciones acusadas en su estado de conservación. Predominan los moldes concrecionales calcáreos, fosfáticos o glauconíticos, con múltiples fases de relleno sedimentario. Sobre las conchas resedimentadas y sobre los moldes reelaborados se desarrollan láminas estromatolíticas calcáreas, a veces fosfáticas y/o ferruginosas, así como organismos cementantes (en particular, serpúlidos, briozoos y ostreidos). Los moldes reelaborados pueden presentar facetas de rodamiento, facetas de truncamiento, facetas elipsoidales de desgaste o surcos anulares. Por procesos de disolución temprana, durante la reelaboración, también se forman moldes concrecionales sin septos. Es frecuente que los elementos formen agrupamientos encajados o imbricados durante los episodios de menor tasa de acumulación de sedimentos, y que las asociaciones muestren granoclasificación cuando están incluidas en depósitos formados por eventos de turbulencia.

\section{MEGASECUENCIAS Y SUPERCICLOS}

Las megasecuencias o los superciclos de segundo orden representan variaciones a largo plazo, del orden de varios millones de años (superior a $5 \mathrm{Ma}$, según Vail et al., 1991 y Rousselle, 1997; superior a 3 Ma, según Jacquin y Vail, 1995; entre 3 y 50 Ma, según Einsele, 1992, Graciansky et al., 1993 y Vera Torres, 1994; más de 2,5 Ma, en Reboulet, 1995; entre 10 y 100 Ma, según Miall, 1995).

Las sucesivas asociaciones registradas de ammonites que constituyen un tafociclo ideal de profundización/ somerización pueden ser agrupadas en dos megatafose- 
cuencias, cada una de las cuales muestra variaciones graduales en sus caracteres secundarios: una megatafosecuencia de profundización y una megatafosecuencia de somerización. Cada megatafosecuencia, a su vez, puede comprender una o más tafosecuencias positivas o negativas. El límite entre las megatafosecuencias de somerización y las megatafosecuencias de profundización, entre sucesivos tafociclos de profundización/somerización, corresponde en el caso extremo a una laguna registrática (es decir, a una laguna de registro de ammonites) que está asociada a una laguna estratigráfica de extensión regional en la plataforma. Sin embargo, un taforregistro de somerización incipiente o media puede estar seguido por un taforregistro de profundización media o avanzada, que representa una nueva megatafosecuencia y un tafociclo distinto. Para interpretar las relaciones entre sucesivas megatafosecuencias y tafociclos, así como para interpretar los episodios de máxima profundización, las distintas megatafosecuencias del mismo orden deben ser integradas en una megatafosecuencia de orden superior, teniendo en cuenta la amplitud de las lagunas registráticas y el desarrollo de los sucesivos taforregistros (Fig. 13).

Cinco tafociclos de profundización/somerización se desarrollaron en las plataformas Castellana, Aragonesa y de Tortosa durante el Jurásico Medio: cuatro de profundización media (durante el Aaleniense inferior, el Aaleniense medio-Bajociense inferior, el Bathoniense y el Calloviense) y uno de profundización avanzada (durante el Bajociense superior). Las discontinuidades principales corresponden al Aaleniense medio (Biocrón Murchisonae) y al Calloviense superior (Biocrón Lamberti). Otras dos discontinuidades de extensión regional corresponden al final del Bajociense (final del Biocrón Parkinsoni) y al final del Bathoniense (Biocrón Discus). Los taforregistros de ammonites de la Biozona Opalinum representan los últimos términos de una megatafosecuencia de somerización iniciada durante el Toarciense superior. Tres megatafosecuencias de profundización se desarrollaron sucesivamente durante los biocronos Murchisonae-Niortense (Aaleniense medioBajociense superior), Zigzag-Progracilis (Bathoniense) y Bullatus-Gracilis (Calloviense).

La máxima profundización y el máximo transgresivo se alcanzaron durante el Biocrón Niortense (Bajociense superior). Los episodios de máxima somerización, que representan máximos regresivos, corresponden a las discontinuidades del Aaleniense medio (Biocrón Murchisonae) y del Calloviense superior (Biocrón Lamberti). Las sucesivas asociaciones registradas comprendidas entre estas dos discontinuidades registráticas de extensión regional, desde el Aaleniense medio hasta el Calloviense superior, constituyen un supertafociclo de segundo orden en la Cuenca Ibérica (Fig. 13). El desarrollo de este superciclo de segundo orden, que está delimitado por dos máximos regresivos, probablemente estuvo influenciado por cambios eustáticos globales (cf. Hallam, 1988; Haq et al., 1988; Norris y Hallam, 1995); sin embargo, los efectos de algunos procesos tectónicos de alcance regional pudieron

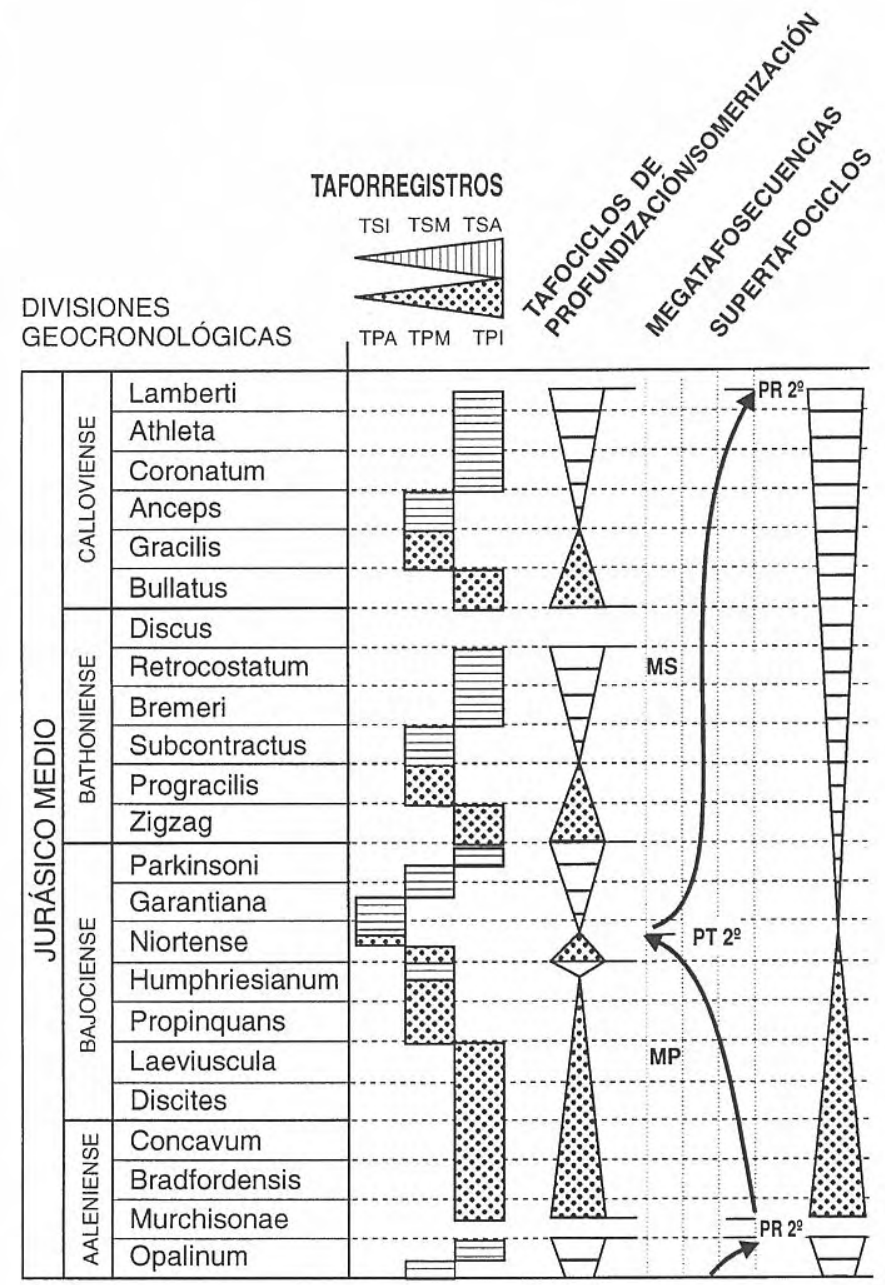

Figura 13. Taforregistros, tafociclos de profundización/somerización y megatafosecuencias identificadas en las asociaciones registradas de ammonites del Jurásico Medio de las plataformas Castellana, Aragonesa y de Tortosa. MP= megatafosecuencia de profundización. MS= megatafosecuencia de somerización. TPI= taforregistro de profundización incipiente. TPM= taforregistro de profundización media TPA $=$ taforregistro de profundización avanzada. $\mathrm{TSI}=$ taforregistro de somerización incipiente. TSA $=$ taforregistro de somerización media. TSA $=$ taforregistro de somerización avanzada. PT $2^{\circ}=$ pico transgresivo de segundo orden. PR $2^{\circ}=$ pico regresivo de segundo orden .

compensar la influencia de dichos cambios eustáticos en algunas plataformas epicontinentales (cf. FernándezLópez \& Gómez, 1990a; Underhill y Partington, 1993; Aurell et al., 1995; Fernández-López et al., 1996).

Los tafociclos y las megatafosecuencias de profundización/somerización establecidas con ammonites permiten identificar ciclos sedimentarios de tercer orden (los llamados ciclos transgresivo/regresivos). El desarrollo de estas megatafosecuencias de profundización y somerización, al igual que el desarrollo de los ciclos sedimentarios de tercer orden, depende de los cambios 
CICLO AMBIENTAL DE PROFUNDIZACIÓN/SOMERIZACIÓN DE TERCER ORDEN

POBLACIONES TAFÓNICAS DE TIPO-1

Emersión y erosión regional
Somerización avanzada
Somerización media
Somerización incipiente
Profundización avanzada
Profundización media
Profundización incipiente
Erosión y emersión regional

CAMBIOS RELATIVOS
DEL NIVEL DEL MAR
profundización - somerización
?.?

ABUNDANCIA RELATIVA creciente - decreciente

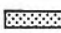

Figura 14. Diacronismo entre los ciclos ambientales de profundización/somerización y la abundancia relativa de poblaciones tafónicas de ammonites de tipo 1 en plataformas epicontinentales carbonáticas. La máxima abundancia de poblaciones tafónicas de tipo 1 se encuentra en los sedimentos formados durante las fases de somerización incipiente.

relativos del potencial de acomodación de sedimentos y de la producción sedimentaria. Las megatafosecuencias de somerización serán más acusadas cuanto menor sea el espacio disponible generado por las fluctuaciones eustáticas y la subsidencia de la plataforma y cuanto mayores sean los aportes sedimentarios. Las megatafosecuencias de profundización serán más acusadas cuanto mayor sea el espacio disponible y la producción sedimentaria.

La identificación de los tafociclos de profundización/ somerización es de máxima importancia para interpretar los ciclos transgresivo/regresivos de las plataformas epicontinentales mesozoicas, donde no suele haber evidencias de las modificaciones de la línea de costa y los sedimentos fosilíferos de plataforma externa están ampliamente desarrollados. Por otra parte, en la misma medida en que el desarrollo de las secuencias deposicionales de tercer orden y de los cortejos sedimentarios o sistemas deposicionales depende del desarrollo de los ciclos transgresivo/regresivos de tercer orden, la identificación de los tafociclos de profundización/ somerización también es útil para reconocer secuencias y sistemas deposicionales de tercer orden. Los taforregistros de profundización media y avanzada se encuentran, respectivamente, en secuencias agradacionales y retrogradacionales. Los taforregistros de somerización incipiente y media se encuentran, respectivamente, en secuencias de relleno y en secuencias progradacionales. Análogamente, las secuencias elementales y las parasecuencias pueden ser identificadas y delimitadas teniendo en cuenta criterios tafonómicos, en particular secuencias tafonómicas elementales y tafosecuencias.

Desde el punto de vista paleoecológico, hay que destacar el diacronismo observado entre los tafociclos de profundización/somerización establecidos con ammonites, los ciclos transgresivo/regresivos de tercer orden y las secuencias deposicionales de tercer orden desarrolladas en las plataformas someras, respecto a la abundancia relativa de poblaciones tafónicas de tipo 1 (Fig. 14). La máxima abundancia y concentración de poblaciones tafónicas de tipo 1 no suele darse en los sedimentos formados durante las fases de profundización avanzada de las plataformas marinas, sino en los sedimentos de las fases de somerización incipiente, cuando los ambientes marinos todavía mantenían los máximos valores de profundidad y pudieron alcanzar los máximos valores de estabilidad. Estos dos factores limitantes, profundidad de las aguas y estabilidad ambiental, debieron condicionar la distribución de los ammonites en las plataformas epicontinentales por ser organismos estenotópicos que corresponden a especies reguladoras. Este diacronismo también pone de manifiesto la mayor capacidad de respuesta de los sistemas sedimentarios, respecto a las poblaciones eudémicas de ammonites, frente a los cambios relativos del nivel del mar.

\section{CONCLUSIONES}

Teniendo en cuenta algunas variaciones en el estado de conservación de las sucesivas asociaciones registradas de ammonites, es posible distinguir secuencias tafonómicas elementales, tafosecuencias, taforregistros, tafociclos, megatafosecuencias y supertafociclos que son el resultado de cambios relativos del nivel del mar. Un tafociclo de profundización/somerización está constituido por dos o más asociaciones-registradas, topológicamente sucesivas y consecutivas, que muestran variaciones cíclicas en sus caracteres secundarios, como resultado de un ciclo de cambio relativo del nivel del mar. Un ciclo tafonómico de este tipo comprende dos hemiciclos: uno de profundización y otro de somerización. Las sucesivas asociaciones registradas de ammonites que constituyen cada uno de estos hemiciclos representan una megatafosecuencia. Para interpretar los episodios de máxima profundización, las sucesivas megatafosecuencias del mismo orden deben ser integradas en una megatafosecuencia de orden superior. Los tafociclos y las megatafosecuencias de profundización/somerización establecidas con ammonites permiten identificar superciclos estratigráficos de segundo orden y secuencias deposicionales de tercer orden.

La identificación de los tafociclos de profundización/ somerización es de máxima importancia para la interpretación de los ciclos transgresivo/regresivos de las plataformas epicontinentales mesozoicas, donde no suele haber evidencias de las modificaciones de la línea de costa y los sedimentos fosilíferos de plataforma externa están ampliamente desarrollados. La identificación de taforregistros y de ciclos tafonómicos, en vez de tafofacies y ciclos estratigráficos, debe realizarse antes de utilizar los datos paleontológicos para interpretar los sedimentos de las plataformas marinas, en análisis de 
estratigrafía secuencial o de estratigrafía genética. Cuando los fósiles reelaborados son frecuentes, las sucesivas asociaciones registradas que constituyen varios taforregistros sucesivos, generados en distintas condiciones ambientales, pueden formar una asociación condensada que se encuentra en un sólo nivel estratigráfico, o pueden corresponder a un episodio o intervalo sin registro estratigráfico.

Cinco ciclos ambientales de profundización/somerización se desarrollaron en las plataformas Castellana, Aragonesa y de Tortosa durante el Jurásico Medio: cuatro de profundización media (durante el Aaleniense inferior, el Aaleniense medio-Bajociense inferior, el Bathoniense y el Calloviense) y uno de profundización avanzada (durante el Bajociense superior). Los taforregistros de ammonites de la Biozona Opalinum representan los últimos términos de una megatafosecuencia de somerización iniciada durante el Toarciense superior. Tres megatafosecuencias de profundización se desarrollaron sucesivamente durante los biocronos Murchisonae-Niortense (Aaleniense-Bajociense superior), Zigzag-Progracilis (Bathoniense) y BullatusGracilis (Calloviense). La máxima profundización y el máximo transgresivo se alcanzaron durante el Biocrón Niortense (Bajociense superior). Los episodios de máxima somerización durante el Jurásico Medio, que representan máximos regresivos, corresponden a las discontinuidades del Aaleniense medio (Biocrón Murchisonae) y del Calloviense superior (Biocrón Lamberti). Los sedimentos del Jurásico Medio comprendidos entre estas dos discontinuidades estratigráficas, desde el Aaleniense medio hasta el Calloviense superior, representan un superciclo de segundo orden en la Cuenca Ibérica.

\section{AGRADECIMIENTOS}

El autor desea expresar su agradecimiento a los doctores F. García Joral (Depto. Paleontología, Facultad de Ciencias Geológicas, Univ. Complutense Madrid), J.C. García Ramos (Área de Estratigrafía, Depto. de Geología, Univ. Oviedo), J.J. Gómez (Depto. de Estratigrafía, Facultad de Ciencias Geológicas, Univ. Complutense Madrid), G. Meléndez (Área de Estratigrafía y Paleontología, Facultad de Ciencias, Univ. Zaragoza), M.S. Ureta (Depto. Paleontología, Facultad de Ciencias Geológicas, Univ. Complutense Madrid) y J.A. Vera Torres (Depto. de Estratigrafía y Paleontología, Facultad de Ciencias, Univ. Granada) por la lectura crítica del manuscrito y las sugerencias recibidas. Este trabajo es una contribución al proyecto PB92-0011 (DGICYT-CSIC).

\section{REFERENCIAS BIBLIOGRÁFICAS}

Aigner, T. 1985. Storm depositional systems: dynamic stratigraphy in modern and ancient shallow-marine sequences. Lecture Notes in the Earth Sciences, 3, 1-174.

Arnott, R.W.C. 1995. The parasequence definition - are transgressive deposits inadequately addressed? Journal of Sedimentary Research, 65, 1-6.

Aurell, M. 1990. El Jurásico superior en la Cordillera Ibérica Central (provincias de Zaragoza y Teruel). Análisis de cuenca. Tesis Doctoral, Departamento de Geología, Servicio de Publicaciones, Universidad de Zaragoza, $389 \mathrm{pp}$.

Aurell, M., Meléndez, A. y Meléndez, G. 1990. Caracterización de la secuencia oxfordiense en el sector central de la Cordillera Ibérica. Geogaceta, 8, 73-76.

Aurell, M., Fernández-López, S. \& Meléndez, G. 1995. The Middle-Upper Jurassic oolitic ironstone level in the Iberian Range (Spain). Eustatic implications. In: $3^{\text {rd }}$ International Symposium on Jurassic stratigraphy, Poitiers, 1991 (Eds. E. Cariou \& P. Hantzpergue). Geobios, M.S. 17 (1994), 549-561.

Baum, G.R. \& Vail, P.R. 1988. Sequence stratigraphic concepts applied to Paleogene outcrop, Gulf and Atlantic basins. In: Sea-level changes: an integrated approach. (Eds. C.K. Wilgus, B.S. Hastings, C.G.St.C. Kendall, H.W. Posamentier, C.A. Ross \& J.C. Van Wagoner). Society of Economic Paleontologists and Mineralogists, Special Publication, 42, 302-327.

Brett, C.E. 1995. Sequence stratigraphy, biostratigraphy, and taphonomy in shallow marine environments. Palaios, 10, 597-616.

Brett, C.E. \& Baird, G.C. 1986. Comparative taphonomy: a key to paleoenvironmental interpretation based on fossil preservation. Palaios, 1, 207-227.

Burchette, T.P. \& Wright, V.P. 1992. Carbonate ramp depositional systems. Sedimentary Geology, 79, 3-57.

Callomon, J.H. 1995. Time from fossils: S.S. Buckman and Jurassic high-resolution geochronology. In: Milestones in Geology (Ed. M.J. Le Bas). Geological Society, London, Memoire, 16, 127-150.

Einsele, G. 1992. Sedimentary basins. Springer, Berlin, 628 pp.

Fels, A. 1995. Prozesse und Produkte geologischer Kondensation im Jura der westlichen Tethys. Profil, 8, 363-472.

Fernández-López, S. 1980. Estudio bioestratigráfico (Ammonoidea) de materiales aalenienses en Ribarroja (Valencia). Estudios Geológicos, 35 (1979), 415-423.

Fernández-López, S. 1983. La biozona Garantiana (Bajociense, Jurásico medio) en la región de TivenysSierra de Cardó (Tarragona). Estudios Geológicos, 38 (1982), 75-93.

Fernández-López, S. 1985a. Criterios elementales de reelaboración tafonómica en ammonites de la Cordillera Ibérica. Acta Geológica Hispánica, 19 (1984), 105-116.

Fernández-López, S. 1985b. Séquences sédimentaires et séquences taphonomiques. Strata, 2, 116-122.

Fernández-López, S. 1985c. El Bajociense en la Cordillera Ibérica. Tesis Doctoral, Departamento de Paleontología, Universidad Complutense de Madrid, 850 pp.

Fernández-López, S. 1986. Sucesiones paleobiológicas y sucesiones registráticas (nuevos conceptos paleontológicos). Revista Española de Paleontología, 1, 29-45.

Fernández-López, S. 1987a. Necrocinesis y colonización posmortal en Bajocisphinctes (Ammonoidea) de la Cuenca Ibérica. Implicaciones paleoecológicas y 
paleobatimétricas. Boletín de la Real Sociedad Española de Historia Natural (Geología), 82, 151-184.

Fernández López, S. 1987 b. Unidades registráticas, Biocronología y Geocronología. Revista Española de Paleontología, 2, 65-85.

Fernández-López, S. 1991. Taphonomic concepts for a theoretical biochronology. Revista Española de Paleontología, 6, 37-49.

Fernández-López, S. 1995. Taphonomie et intreprétation des paléoenvironnements. In: First European Palaeontological Congress, Lyon, 1993 (Eds. M. Gayet \& B. Courtinat). Geobios, M.S. 18, 137-154.

Fernández-López, S. 1997. Ammonites, clinos tafonómicos y ambientes sedimentarios. Revista Española de Paleontología, 12, 102-128.

Fernández-López, S. y Aurell, M. 1988. El Bajociense y Bathoniense de Ricla (Zaragoza): características bioestratigráficas y sedimentológicas. Ciencias de la Tierra, 11, 251-264.

Fernández-López, S. et Gómez, J.J. 1990a. Evolution tectono-sédimentaire et gènese des associations d'Ammonites dans le secteur central du Bassin Ibérique (Espagne) pendant l'Aalénien. Cahiers de l'Université Catholique de Lyon, sér. sci., 4, 39-52.

Fernández-López, S. y Gómez, J.J. 1990b. Utilidad sedimentológica y estratigráfica de los fósiles reelaborados. In: Comunicaciones de la Reunión de Tafonomía y Fosilización (Coord. S. Fernández-López). Departamento de Paleontología, Universidad Complutense de Madrid, 125-144.

Fernández-López, S. y Gómez, J.J. 1990c. Facies aalenienses y bajocienses, con evidencias de emersión y carstificación, en el sector central de la Cuenca Ibérica. Implicaciones paleogeográficas. Cuadernos de Geología Ibérica, 14, 67-111.

Fernández-López, S. y Gómez, J.J. 1991. Condensación: significados y aplicaciones al análisis de cuencas. Estudios Geológicos, 47, 169-181.

Fernández-López, S. \& Meléndez, G. 1994. Abrasion surfaces on internal moulds of ammonites as palaeobathymetric indicators. Palaeogeography, Palaeoclimatology, Palaeoecology, 110, 29-42.

Fernández-López, S. y Meléndez, G. 1995a. Dispersión biogeográfica y tafonómica de ammonoideos filoceratinos hacia la Cuenca Ibérica durante el Jurásico Medio. Coloquios de Paleontología, 46 (1994), 129-149.

Fernández-López, S. \& Meléndez, G. 1995b. Taphonomic gradients in Middle Jurassic ammonites of the Iberian Range (Spain). In: First European Palaeontological Congress, Lyon, 1993 (Eds. M. Gayet \& B. Courtinat). Geobios, M.S. 18, 155-165.

Fernández-López, S. \& Meléndez, G. 1996. Phylloceratina ammonoids in the Iberian Basin during the Middle Jurassic: a model of biogeographical and taphonomic dispersal related to relative sea-level changes. Palaeogeography, Palaeoclimatology, Palaeoecology, 120, 291-302.

Fernández-López, S. et Mouterde, R. 1985. Le Toarcien, l'Aalénien et le Bajocien dans le secteur de Tivenys: nouvelles données biostratigraphiques. Strata, 2, 71-82.
Fernández-López, S. et Mouterde, R. 1994. L_Horizon à Gervillii (Bajocien inférieur) de Tendron (Cher, France). Taphonomie et populations d'ammonites. Proceedings $3^{\text {rd }}$ International Meeting on Aalenian and Bajocian Stratigraphy. Miscellanea del Servizio Geologico Nazionale, 5, 117-159.

Fernández-López, S. y Suárez-Vega, L.C. 1980. Estudio bioestratigráfico (Ammonoidea) del Aaleniense y Bajociense en Asturias. Estudios Geológicos, 35 (1979), 231-239.

Fernández-López, S., Meléndez, G. y Suárez-Vega, L.C. 1978. El Dogger y Malm en Moscardón (Teruel). Grupo Español de Mesozoico, Guía de excursiones Jurásico Cordillera Ibérica, VI, 1-20.

Fernández-López, S., Gómez, J.J. et Goy, A. 1985. Le Dogger de Caudiel (Castellón): sédimentologie des carbonates développés sur un "monticule" de matériaux volcaniques. Strata, 2, 101-115.

Fernández-López, S., Gómez, J.J. y Ureta, M.S. 1988. Características de la plataforma carbonatada del Dogger en el sector meridional de la Sierra de La Demanda (Soria). Ciencias de la Tierra, 11, 167-195.

Fernández-López, S., Aurell, M., García Joral, F., Gómez, J.J., Henriques, M.H.P., Martínez, G., Meléndez, G. y Suárez Vega, L.C. 1996. El Jurásico Medio de la Cuenca Catalana: unidades litoestratigráficas y elementos paleogeográficos. Revista Española de Paleontología, $\mathrm{n}^{\circ}$ extraordinario, 122-139.

Ferry, S. 1991. Une alternative au modèle de stratigraphie séquentielle d'Exxon: la modulation tectono-climatique des cycles orbitaux. Géologie alpine, 18, h.s., 47-99.

Ferry, S. et Mangold, Ch. 1995. Faciès de dépôt et Stratigraphie Séquentielle des calcaires bajociens du Jura Méridional. Documents des Laboratoires de Géology Lyon, 133, 1-96.

Fürsich, F.T. \& Oschmann, W. 1993. Shell beds as tools in basin analysis: the Jurassic of Kachchh, estern India. Journal of the Geological Society, London, 150, 169185.

García-Ramos, J.C., Valenzuela, M. y Suárez de Centi, C. 1992. Rampa carbonatada del Jurásico de Asturias. Reunión monográfica sobre Biosedimentación. Departamento de Geología, Universidad de Oviedo, 50 pp.

Gómez, J.J. 1979. El Jurásico superior en facies carbonatadas del sector levantino de la Cordillera Ibérica. Tesis Doctoral, Universidad Complutense de Madrid. Seminarios de Estratigrafía (serie monografías), 4, 1-683.

Gómez, J.J. y Fernández-López, S. 1992. Secciones condensadas y máximos transgresivos: una relación equívoca. Geogaceta, 11, 130-137.

Gómez, J.J. \& Fernández-López, S. 1994. Condensation processes in shallow platforms. Sedimentary Geology, 92, 147-159.

Gonnin, Ch., Cariou, E. et Branger, P. 1992. Les facteurs de contrôle de la sédimentation au début du Jurassique moyen sur le seuil du Poitou et ses abords. Comptes Rendus de l'Academie des Sciences de Paris, 315, 853859. 
Gonnin, Ch., Cariou, E. et Branger, P. 1993. Stratigraphie séquentielle des séries du Bajocien inférieur au Bathonien moyen su seuil du Poitou et de son versant aquitain (France). Comptes Rendus de l'Academie des Sciences de Paris, 316, 209-215.

Goy, A., Ureta, S., Arias, C., Canales, M.L., García Joral, F., Herrero, C., Martínez, G. \& Perilli, N. 1994. The Fuentelsaz section (Iberian range, Spain), a posible stratotype for the base of the Aalenian stage. Miscellanea del Servizio Geologico Nazionale, 5, 1-31.

Graciansky, P.Ch., Dardeau, G., Dumont, T., Jacquin, T., Marchand, D., Mouterde, R. \& Vail, P.R. 1993. Depositional sequence cycles, transgressive-regressive facies cycles, and extensional tectonics: example from the southern Subalpine Jurassic basin, France. Bulletin de la Société géologique de France, 164, 709-718.

Gradstein, F.M., Agterberg, F.P., Ogg, J.G., Hardenbol, J., Veen, P. van, Thierry, J. \& Huang, Z. 1994. A Mesozoic time scale. Journal of Geophysical Research, 99, 24.05124.074 .

Gradstein, F.M. \& Ogg, J. 1996. A Phanerozoic time scale. Episodes, 19, 3-5.

Hallam, A., 1988. A reevaluation of Jurassic eustasy in the ligth of new data and the revised Exxon curve. In: SeaLevel Changes: An Integrated Approach (Eds. C.K. Wilgus, B.S. Hastings, C.G.S.C. Kendall, H. Posamentier, C.A. Ross \& J.C. Van Wagoner). Society of Economic Paleontologists and Mineralogists, Special Publication, 42, 261-273.

Handford, C.R. \& Loucks, R.G. 1993. Carbonate depositional sequences and systems tracts - Responses of carbonate platforms to relative sea-level changes. In: Carbonate sequence stratigraphy (Eds. R.G. Loucks \& J.F. Sarg). American Association of Petroleum Geologists, Memoire, 57, 3-41.

Haq, B.U., Hardenbol, J. and Vail, P.R., 1988. Mesozoic and Cenozoic Chronostratigraphy and Eustatic Cycles. In: Sea-Level Changes: An Integrated Approach (Eds. C.K. Wilgus, B.S. Hastings, C.G.S.C. Kendall, H. Posamentier, C.A. Ross \& J.C. Van Wagoner). Society of Economic Paleontologists and Mineralogists, Special Publication, 42, 71-108.

Homewood, P.W. 1996. The carbonate feedback system: interaction between stratigraphic accommodation, ecological succesion and the carbonate factory. Bulletin de la Société géologique de France, 167, 701-715.

Homewood, P., Guillocheau, F., Eschard, R. et Cross, T.A. 1992. Corrélations haute résolution et stratigraphie génétique: une démarche intégrée. Bulletin des Centres de Recherche et Exploration-Production Elf Aquitaine, 16, 357-381.

Jacquin, T. \& Vail, P.R. 1995. Shelfal accommodation as a major control on carbonate platforms. Bulletin de la Société géologique de France, 166, 423-435.

Jacquin, T., García, J.P., Ponsot, C., Thierry, J. et Vail, P.R. 1992. Séquences de dépôt et cycles régressif/transgressifs en domaine marin carbonaté: exemple du Dogger du Bassin de Paris. Comptes Rendus de l'Academie des Sciences de Paris, 315, 353-362.
James, N.P. 1983. Depositional models for carbonate rocks. In: Sediment Diagenesis (Eds. A. Parker \& B.W. Sellwood). Reidel Publishing Company, Boston, 289348.

Kowalewski, M. 1996. Time-averaging, overcompleteness, and the geological record. The Journal of Geology, 104, 317-326.

Lardiés, M.D. 1990. Observaciones bioestratigráficas y sedimentológicas sobre el Calloviense en la provincia de Zaragoza. Cuadernos de Geología Ibérica, 14, 157-172.

López Martínez, N. \& Fernández López, S. 1993. Geological Biochronology and temporal correlations. Geoprep Course Publications, Tremp (Lleida), 1, 1-69.

McKinney, M.L. 1985. Distinguishing patterns of evolution from patterns of deposition. Journal of Paleontology, 59, 561-567.

Meléndez, G. 1989. El Oxfordiense en el sector central de la Cordillera Ibérica (Provincias de Zaragoza y Teruel). Instituto Estudios Turolenses, Zaragoza-Teruel, 418 pp.

Meléndez, G., Aurell, M., Fontana, B. y Lardiés, D. 1990. El tránsito Dogger-Malm en el sector nororiental de la Cordillera Ibérica: Análisis tafonómico y reconstrucción paleogeográfica. In: Comunicaciones de la Reunión de Tafonomía y Fosilización (Coord. S. Fernández-López). Departamento de Paleontología, Universidad Complutense de Madrid, 221-229.

Miall, A.D. 1995. Whither stratigraphy? Sedimentary Geology, 100, 5-20.

Miall, A.D. 1997. The geology of stratigraphic sequences. Springer, Berlin, 433 pp.

Monaco, P. 1995. Hummocky cross-stratifications and trace fossils in the Middle Toarcian of some sequences of Umbria-Marche Apennines. In: $3^{\text {rd }}$ International Symposium on Jurassic stratigraphy, Poitiers, 1991 (Eds. E. Cariou \& P. Hantzpergue). Geobios, M.S. 17 (1994), 679-688.

Norris, M.S. \& Hallam, A. 1995. Facies variations across the Middle-Upper Jurassic boundary in Western Europe and the relationship to sea-level changes. Palaeogeography, Palaeoclimatology, Palaeoecology, 116, 189-245.

Odin, G.S., Galbrun, B. \& Renard, M. 1995. Physicochemical tools in Jurassic stratigrapgy. In: $3^{r d}$ International Symposium on Jurassic stratigraphy, Poitiers, 1991 (Eds. E. Cariou \& P. Hantzpergue). Geobios, M.S. 17 (1994), 507-518.

Ramajo, J. y Meléndez, G. 1996. El límite CallovienseOxfordiense en Ricla (Zaragoza). Análisis sedimentológico y tafonómico de una sucesión condensada rica en ammonoideos. In: Comunicaciones de la II Reunión de Tafonomía y Fosilización (Eds. G. Meléndez Hevia, M.F. Blasco Sancho e I. Pérez Urresti). Institución "Fernando el Católico", Zaragoza, 337-346.

Reboulet, S. 1995. L'évolution des ammonites du Valanginien-Hauterivien inférieur du Bassin Vocontien et de la Plate-forme Provençale (sud-est de la France): relations avec la stratigraphie séquentielle et implications biostratigraphiques. Documentes du Láboratoire de Géologie, Université de Lyon, 137, 1-371.

Rioult, M., Dugue, O., Du Chene, J., Ponsot, C., Fily, G., Moron, J.-M. \& Vail, P.R., 1991. Outcrop Sequence 
stratigraphy of the Anglo-Paris Basin Middle to Upper Jurassic (Normandy, Maine, Dorset). Bulletin des Centres de Recherche et Exploration-Production Elf Aquitaine, 15, 101-194.

Rousselle, B. 1997. Partition stratigraphique des faciès et des volumes de dépôt en domaine de plate-forme carbonatée: exemples dans l'Aalénien du Sud-Est de la France. Documents des Laboratoires de Géologie de Lyon, 143, 1-225.

Sadler, P.M. 1981. Sediment accumulation rates and the completeness of stratigraphic sections. The Journal of Geology, 89, 569-584.

Schindel, D.L. 1982. Resolution analysis: a new approach to the gaps in the fossil record. Paleobiology, 8, 340-353.

Sequeiros, L. y Meléndez, G. 1987. El Calloviense de los Ibérides (Dominio Ibérico, España). Síntesis bioestratigráfica. Estudios geológicos, 43, 95-105.

Sequeiros, L., Cariou, E. y Meléndez, G. 1984. Algunos ammonoideos del Calloviense superior de Aguilón (Zaragoza, Cordillera Ibérica). Estudios geológicos, 40, 399-410.

Tipper, J.C. 1987. Estimating stratigraphic completeness. Journal of Geology, 95, 710-715.

Underhill, J.R. \& Partington, M.A. 1993. Jurassic thermal doming and deflation in the North Sea: implications of the sequence stratigraphic evidence. In: Petroleum
Geology of Northwest Europe (Ed. J.R. Parker). The Geological Society, London, 337-345.

Vail, P.R., Colin, J.P., Chene, R.J. du, Kuchly, J., Mediavilla, F. et Trifilieff, V. 1987. La stratigraphie séquentielle et son application aux corrélations chronostratigraphiques dans le Jurassique du bassin de Paris. Bulletin de la Société géologique de France (8), 3, 1301-1321.

Vail, P.R., Audemard, F., Bowman, S.A., Eisner, P.N. \& Pérez-Cruz, C. 1991. The stratigraphic signatures of tectonics, eustasy and sedimentology - an overview. In: Cycles and event in Stratigraphy (Eds. G. Einsele, W. Ricken \& A. Seilacher). Springer, Berlin, 83-97.

Vera Torres, J.A. 1994. Estratigrafía. Principios y métodos. Editoriar Rueda, Madrid, 806 pp.

Wilgus, C.K., Hastings, B.S., Kendall, C.G.St.C., Posamentier, H.W., Ross, C.A. \& Van Wagoner, J.C. 1988. Sea-level changes: an integrated approach. Society of Economic Paleontologists and Mineralogists, Special Publication, 42, 1-407.

Wilson, J.L. 1975. Carbonate facies in Geologic History. Springer, Berlín, 471 pp.

Wright, V.P. \& Burchette, T.P. 1996. Shallow-water carbonate environments. In: Sedimentary Environments: processes, facies and stratigraphy (Ed. H.G. Reading). Blackwell, Oxford, 325-394. 